\title{
Caspase-3 Deficiency Results in Disrupted Synaptic Homeostasis and Impaired Attention Control
}

\author{
Shih-Ching Lo, ${ }^{1}$ Yuanyuan Wang, ${ }^{1}$ Martin Weber, ${ }^{1}$ Jessica L. Larson, ${ }^{2}$-Kimberly Scearce-Levie, ${ }^{1}$ and Morgan Sheng ${ }^{1}$ \\ Departments of ${ }^{1}$ Neuroscience, and ${ }^{2}$ Bioinformatics and Computational Biology, Genentech Inc., South San Francisco, California 94080
}

The ability to attend to relevant stimuli and to adapt dynamically as demands change is a core aspect of cognition, and one that is impaired in several neuropsychiatric diseases, including attention deficit/hyperactivity disorder. However, the cellular and molecular mechanisms underlying such cognitive adaptability are poorly understood. We found that deletion of the caspase- 3 gene, encoding an apoptosis protease with newly discovered roles in neural plasticity, disrupts attention in mice while preserving multiple learning and memory capabilities. Attention-related deficits include distractibility, impulsivity, behavioral rigidity, and reduced habituation to novel stimuli. Excess exploratory activity in Casp $3^{-1-}$ mice was correlated with enhanced novelty-induced activity in the dentate gyrus, which may be related to our findings that caspase- 3 is required for homeostatic synaptic plasticity in vitro and homeostatic expression of AMPA receptors in vivo in response to chronic or repeated stimuli. These results suggest an important role for caspase-3 in synaptic suppression of irrelevant stimuli.

Key words: ADHD; attention control; caspase-3; homeostatic synaptic plasticity; LTD; novelty habituation

\section{Introduction}

The ability to reorient attention and adjust the course of action when environmental stimuli change is critical for organisms to adapt in a complex and dynamic environment. Selection of the highest priority stimuli for attention while suppressing others is determined by biased competition among all processed stimuli based on their salience or relevance, such as intensity, motion, or novelty, and is guided internally by knowledge, goals, or expectations (Desimone and Duncan, 1995). Attentional processing develops rapidly through childhood and continues to mature during adolescence (Jurado and Rosselli, 2007), and its impairment is associated with multiple neurodevelopmental disorders, including autism, fragile X syndrome, schizophrenia, bipolar disorder, and attention-deficit/hyperactivity disorder (ADHD; Ewen and Shapiro, 2005). Attention lapses are often correlated with disrupted competitive suppression of network activity (Weissman et al., 2006; Corbetta et al., 2008). It has been hypothesized that several forms of synaptic plasticity contribute to the suppression of neural activity during attention processing, but

Received Aug. 8, 2014; revised Dec. 4, 2014; accepted Dec. 17, 2014.

Author contributions: S.-C.L., K.S.-L., and M.S. designed research; S.-C.L. and Y.W. performed research; M.W. contributed unpublished reagents/analytic tools; S.-C.L., Y.W., and J.L.L. analyzed data; S.-C.L., K.S.-L., and M.S. wrote the paper.

We thank Jesse Hanson and David Hackos for critically reading the manuscript; Tiffany Wu, Hilda Solanoy, Han Lin, and Raniel Alcantara for assistance with experiments; Melissa Gonzalez-Edick for assistance with whole slide imaging; Hai Ngu for assistance with Matlab algorithm; Raymond Asuncion and Chung Kung for mouse breeding; and Richard Flavell for providing caspase-3-deficient mice.

The authors are employees of Genentech Inc., a member of the Roche Group.

Correspondence should be addressed to either of the following: Shih-Ching Lo, 1 DNA Way, MS 230B, South San Francisco, CA 94080, E-mail: shihchil@gene.com; or Kimberly Scearce-Levie, 1 DNA Way, MS 230A, South San Francisco, CA 94080.E-mail: kimbers@gene.com.

DOI:10.1523/JNEUROSCI.3280-14.2015

Copyright $\odot 2015$ the authors $\quad 0270-6474 / 15 / 352118-15 \$ 15.00 / 0$ this has not yet been tested (Desimone, 1996; Grill-Spector et al., 2006).

Experience-dependent, long-lasting changes in synaptic strength are important for CNS development, and underlie information encoding and storage in the brain. Long-term potentiation (LTP) and long-term depression (LTD), two major forms of Hebbian plasticity, have been extensively studied. The role of LTP in learning and memory is widely recognized; however, the significance of LTD remains enigmatic. Recent evidence suggests that LTD plays a role in more complex domains of cognition, including novelty exploration and behavioral flexibility (Kemp and Manahan-Vaughan, 2008; Nicholls et al., 2008; Collingridge et al., 2010; Kim et al., 2011; Dong et al., 2012, 2013).

The positive feedback nature of Hebbian plasticity could lead to runaway excitation or depression of neurons, and result in network instability. Homeostatic synaptic plasticity, such as synaptic scaling, is generally evoked to prevent such destabilization (Turrigiano, 2012). Although synaptic scaling and Hebbian plasticity share many common molecular players (Vitureira and Goda, 2013; Siddoway et al., 2014), the physiological roles of homeostatic synaptic plasticity in vivo remain largely unknown.

Caspase-3 (Casp3) is a cysteine-aspartate protease that, when activated, targets specific substrates for proteolysis, and executes apoptotic cell death. Accumulating evidence points to functions for caspase-3 in cellular remodeling processes that are independent of apoptotic cell death, including dendritic pruning, metaplasticity, and NMDA receptor-dependent LTD (NMDA-LTD; Li et al., 2010; D'Amelio et al., 2012; Hyman and Yuan, 2012; Ertürk et al., 2014). However, it is still not clear how these specific modulations of functional or morphological plasticity affect the behavior and cognition of the whole organism. While studying the nonapoptotic functions of caspase-3, we unexpectedly discovered that caspase- 3 deficiency in mice (C57BL/6) affects spe- 
cific aspects of cognition and behavior, particularly attention and inhibitory control. In addition, we found that caspase- 3 is critical for synaptic homeostasis, and that disrupted homeostatic AMPA receptor expression and escalated regional neural activity correlate with impaired behavioral inhibitory control. Our studies of caspase-3 deficiency provide fresh insights into the cellular and molecular mechanisms underlying suppression of irrelevant or excessive stimuli necessary for efficient attention control.

\section{Materials and Methods}

\section{Animals and general procedures}

Casp $3^{-1-}$ founder mice were purchased from the The Jackson Laboratory (stock \#006233; laboratory of R. Flavell, Yale University, New Haven, CT). Mice were backcrossed for at least eight generations to C57BL/6 mice. Heterozygous mice were crossed to generate Casp $3^{-1-}$ mice and age-matched wild-type (WT) littermates. Mice were housed in a specific pathogen-free barrier facility on a 14/10 h light/dark cycle. Group housing was maintained, except where noted. Food and water were freely available, except where noted. Behavioral testing occurred between 8:00 A.M. and 6:00 P.M. Male mice were used throughout the study, except where noted in Materials and Methods (see subsections Object habituation and dishabituation and Novel object exploration and recognition). Mice were subjected to $2 \mathrm{~min}$ of handling habituation daily for 3 consecutive days before behavioral testing. All equipment was thoroughly cleaned with $70 \%$ ethanol and water wipes between testing of individual mice to standardize odors, except where noted. Experimenters were blind to genotype. All experiments were approved by the Genentech Animal Care and Use Committee, and followed the National Institutes of Health Guide for the Care and Use of Laboratory Animals.

\section{Five-choice serial reaction time task}

Subjects. Mice (16 WT mice and 16 Casp $3^{-1-}$ mice) were individually housed and maintained at $\sim 80 \%$ of their weight by restricting the amount of food pellets, starting $5 \mathrm{~d}$ before the experiment. Water was available ad libitum.

Apparatus. Experiments were conducted in eight identical mouse fivehole, nose-poke operant chambers, each housed within a ventilated sound-attenuated box (Campden Instruments). The rear wall of the chamber incorporated nine equally spaced holes in a horizontal array, with four inactive holes covered with a plastic film. A stimulus light diode illuminating each of these holes was used as a visual cue. A liquid reward ( $20 \mu \mathrm{l}$ of strawberry milkshake) was provided as reinforcement. A house light mounted above the reward magazine illuminated the test chamber during time-out punishment. Animals were tested in one daily session, 5-7 d/week.

Shaping. Mice were introduced to the liquid reinforcer once in their home cages $4 \mathrm{~d}$ before the beginning of the experiment. During the six shaping sessions, mice continuously received $40 \mu \mathrm{l}$ of the reinforcer delivered to the magazine every $40 \mathrm{~s}$ on days 1 and 2 , and then $20 \mu \mathrm{l}$ of the reinforcer delivered every $60 \mathrm{~s}$ on days 3 and 4 . On days 5 and 6 , every delivery of the $20 \mu \mathrm{l}$ of liquid reinforcer was paired with a stimulus light illuminating the center aperture for $10 \mathrm{~s}$ immediately before delivery. Each session lasted for $30 \mathrm{~min}$, or up to 100 reinforcer deliveries, whichever occurred first.

Training. Mice were trained in eight phases to perform a nose-poke response to a visual cue. In phase 1, only the two holes adjacent to the center hole were accessible, and one of these holes was illuminated in a pseudorandom order for $32 \mathrm{~s}$, or until a nose-poke response was made. Animals were required to respond during the presentation of the stimulus light, or within $5 \mathrm{~s}$ after termination of the cue. Nose poking into the illuminated hole was considered a correct response, and was rewarded. After collecting rewards, nose withdrawal from the food magazine initiated an intertrial interval (ITI) of $5 \mathrm{~s}$, during which all the lights remained off. Nose poking into a nonilluminated hole was considered an incorrect response, and was followed by termination of the trial without delivery of a reward. If an animal did not make a response into any of the holes during stimulus presentation or the limited hold, an omission was counted. Nose poking into any hole during the ITI was considered a premature response. Incorrect responses, omissions, and premature responses resulted in a time-out period of $5 \mathrm{~s}$, and were automatically followed by the start of an ITI. Each session lasted for $25 \mathrm{~min}$, or 100 trials if completed sooner. Before progressing to phase 2 of training, the mice were required to reach the performance criterion of $\geq 80 \%$ accuracy, $\leq 20 \%$ omission, and $\geq 40$ correct responses for 2 consecutive days. If an animal failed to make more than seven correct responses for 2 consecutive days or failed to reach criterion performance in $8 \mathrm{~d}$, it was given remedial training, during which only the center hole was illuminated for nose-poking responses, and the animal was required to make $\geq 40$ correct responses for 2 consecutive days before resuming training with two accessible holes.

In phase 2, one of the five nose-poke holes was illuminated in pseudorandom order, and the mice were required to reach the performance criterion of $\geq 80 \%$ accuracy, $\leq 20 \%$ omission, and $\geq 60$ correct responses for 2 consecutive days.

In phases 3-7, mice were required to initiate the ITI via a nose poke in the food magazine following each time-out period. The stimulus duration was initially $32 \mathrm{~s}$, and progressively decreased to $16,8,4$, and 3 s once the subject reached the criterion performance of $\geq 80 \%$ accuracy, $\leq 20 \%$ omission, and $\geq 60$ correct responses for 2 consecutive days for each of these training stages.

In phase 8 , the stimulus duration was $2 \mathrm{~s}$, and successful acquisition of the task was defined as reaching the baseline criterion performance of $\geq 80 \%$ accuracy, $\leq 20 \%$ omission, and $\geq 50$ correct responses for 2 consecutive days. Baseline performance of the newly acquired task was reflected in the following behavioral measurements: (1) accuracy (i.e., the percentage of correct responses), calculated as [number of correct responses/(correct + incorrect responses)] $\times 100$; (2) correct response latency; (3) percentage of omission, calculated as [number of omitted responses/(correct + incorrect + omitted responses)] $\times 100$; (4) percentage of premature responses, calculated as [number of premature responses/(correct + incorrect + omitted + premature responses $)] \times$ 100; and (5) reward collection latency, an indicator of general response velocity and motivation to perform the task.

Testing. Baseline performance was maintained for 4 additional days at the end of training, and again in between testing sessions. Only the animals that maintained baseline performance at the criterion for 2 consecutive days proceeded to the subsequent testing session. First, the mice (16 WT mice and 16 Casp3 ${ }^{-1-}$ mice) were challenged with a series of variable stimulus duration $(0.7,0.6,0.5$, and $0.3 \mathrm{~s})$ in a pseudorandom order. The ITI remained at $5 \mathrm{~s}$. One WT nonperformer whose reward collection latency was greater than the third quartile by $>1.5$-fold of the interquartile range was excluded from final analysis. One Casp3 ${ }^{-1-}$ mouse was found dead in the home cage before the experimental series was concluded. Next, mice (15 WT mice and 15 Casp $3^{-1-}$ mice) were challenged with variable ITIs of 6 and $12 \mathrm{~s}$ in a pseudorandom order. The stimulus duration was $0.7 \mathrm{~s}$. In a visual distraction test, mice (15 WT mice and 15 Casp $3^{-1-}$ mice) were challenged with distractor lights of $0.7 \mathrm{~s}$ during the ITI for $80 \%$ of the trials. The distractor lights illuminated the four inaccessible alternate holes starting $0.3,2.5,4.3$, or $5.0 \mathrm{~s}$ following the onset of the ITI in a pseudorandom order. Six WT mice could no longer maintain baseline performance at the criterion level after this visual distraction test, and hence did not proceed to further testing. Finally, in a subsequent visual distraction testing session, mice (9 WT mice and 15 Casp3 $^{-1-}$ mice) were challenged with distractor lights of $0.7 \mathrm{~s}$ during the ITI for only half of the trials. The distractor lights were turned on consistently at $4.3 \mathrm{~s}$ following the onset of the ITI. The ITI remained at $5 \mathrm{~s}$ and the stimulus duration at $0.7 \mathrm{~s}$ for both visual distractor sessions. The majority of tested animals ( 22 of 24) completed $>40-60$ trials during the session, and their response accuracy was analyzed in three 20 -trial bins.

\section{Morris water maze and spatial reversal learning task}

The circular pool (122 cm in diameter) was surrounded by extra-maze cues, and contained opaque water $\left(18-20^{\circ} \mathrm{C}\right)$ with a circular escape platform $(11.5 \mathrm{~cm}$ in diameter) submerged $1.5 \mathrm{~cm}$ below the surface. Three days before the experiment, individually housed mice were subjected to pretraining of four trials during which they were required to swim down a rectangular channel $(12 \times 120 \mathrm{~cm})$, and mount onto the platform 
located midway. One Casp $3^{-/-}$mouse could not complete pretraining, and hence did not proceed to the experiment. Mice (20 WT mice and 19 Casp3 ${ }^{-1-}$ mice) were then trained to locate the hidden platform over 5 consecutive days (two sessions of three trials per day, 3-4 h between sessions). The platform location remained the same throughout training, and entry points were changed pseudorandomly between trials. Mice that failed to locate the platform during the $60 \mathrm{~s}$ trial were guided to the platform. Approximately $16 \mathrm{~h}$ after the last training session, the platform was removed, and a $60 \mathrm{~s}$ probe trial was performed. Immediately following the probe trial, spatial reversal learning task was conducted in which the platform was moved to the opposite quadrant of the pool, and the mice were trained to locate the new platform in four sequential $60 \mathrm{~s}$ trials (15 min between trials). The latency to locate the platform, the distance traveled, and swim speeds were recorded and analyzed by an automated tracking program (TopScan, CleverSys). Two WT nonperformers whose average swim speeds during training were below the first quartile by $>1.5$-fold of the interquartile range were excluded from final analysis.

\section{Attentional set shifting task}

The open-topped gray plastic arena $(30.5 \times 45.7 \times 30.5 \mathrm{~cm})$ was divided into a large waiting compartment $(30.5 \times 30.5 \mathrm{~cm})$ and two smaller choice compartments $(15.2 \times 15.2 \mathrm{~cm})$ at one end of the arena. Each choice compartment was accessible from the waiting compartment through a sliding guillotine-type door and contained a small food bowl (6.4 $\mathrm{cm}$ in diameter; $3.8 \mathrm{~cm}$ in height), holding a food reward buried beneath different scented media. The presence or absence of the reward is indicated either through tactile stimuli (Alpha-dri vs plastic beads) or olfactory stimuli (cinnamon vs onion). Mice (15 WT mice and 15 Casp3 ${ }^{-1-}$ mice) were individually housed and maintained at $\sim 80 \%$ of their initial weight by restricting the amount of food pellets. The food reward and the food bowl were first introduced to mice in their home cage. Before training, mice were habituated to the test arena for one 10 min session. Mice were trained to dig reliably for the food reward in 12 consecutive trials, during which the food reward was first placed on the surface of the digging medium (bed-o'cobs) and gradually placed deeper with each successive trial (trials 2-6) until fully buried for another six trials (trials 7-12).

During discrimination tests, each trial started upon opening of the sliding door, and the mouse was allowed to freely investigate the two food bowls, one of which was baited with a reward. In the first four pretrials, the mouse was allowed to dig in both bowls. Afterward, the mouse was allowed to dig in one bowl only. If the mouse dug in the baited bowl, the mouse was allowed to consume the reward and a correct response was recorded; if the mouse dug in the unbaited bowl, the trial was terminated and an error was recorded. The side of stimulus presentation, the rewarded modality, and the rewarded cue were all counterbalanced pseudorandomly across the study. When the mouse reached the criterion of six consecutive correct trials, the discrimination test session was completed, and the total number of trials and errors were analyzed. Mice were tested in a series of three discriminations in the following order: (1) simple discrimination (SD), in which the bowls differed only along one of the two dimensions, digging medium or odor, and Bed-o'cobs was used as the digging medium in both bowls throughout odor discrimination and hence presented no predictive value for reward; (2) compound discrimination (CD), in which both dimensions of odor and digging medium were introduced, but the relevant dimension and correct/erroneous stimuli remained the same as for SD; and (3) compound reversal (CDR), in which both dimensions remained present and the relevant dimension remained unchanged, but the previously correct and erroneous stimuli were switched.

Mice were tested in CD 1-2 d after SD was completed, and were tested in CDR 3-4 h after CD was completed.

\section{Open field and novel environment}

Mice (21 WT mice and 13 Casp3 ${ }^{-1-}$ mice) were placed in a novel open chamber $(40.6 \times 40.6 \times 38.1 \mathrm{~cm})$ made of clear plastic for $1 \mathrm{~h}$. Locomotor activities were monitored by a $16 \times 16$ photobeam system (PAS-Open Field, San Diego Instruments). In a different testing room, mice were placed in a novel open chamber $(40 \times 40 \times 35 \mathrm{~cm})$ made of opaque gray plastic for
$15 \mathrm{~min}$. Each mouse was placed in the same chamber again for $15 \mathrm{~min}$ on days 4 and 8. Locomotor activities were recorded from a camera mounted overhead and analyzed by an automated tracking program (TopScan, CleverSys).

Mice (11 WT mice and 7 Casp $3^{-1-}$ mice) assigned to novel environment exploration were placed in a larger cage $(26 \times 48.3 \times 20.3 \mathrm{~cm})$ in a novel testing room. The new cages contained different bedding ( $\alpha$-dry), and five novel objects. The mice were free to explore for $2 \mathrm{~h}$. The remaining mice (10 WT mice and 5 Casp $3^{-/-}$mice) stayed undisturbed in their home cages.

\section{Object habituation and dishabituation}

Mice (WT mice: 12 males and 6 females; Casp3 ${ }^{-1-}$ mice: 13 males and 6 females) were habituated to an empty arena $(40 \times 40 \times 35 \mathrm{~cm})$ before the experiment. Three sets of plastic objects (objects A-C) with distinct colors and shapes were used as novel objects in a pseudorandom order. Object A was placed in the center of the arena, and the mice were free to explore for $4 \mathrm{~min}$. Then, the object was removed, and the mouse was left in the arena for $2 \mathrm{~min}$. An exact duplicate of object A was reintroduced to the arena for $4 \mathrm{~min}$. This procedure was repeated for a total of three presentations. On the fourth trial, object B was introduced, and the sequence of three presentations was repeated. Object $C$ was introduced in the final trial. Exploration of an object was defined as climbing on the object, or as when a mouse oriented toward the object with a distance between the nose and the object of $<1 \mathrm{~cm}$. The time spent exploring an object was recorded from a camera mounted overhead and was analyzed by an automated tracking program (TopScan, CleverSys) for the first $60 \mathrm{~s}$ of each trial.

\section{Novel object exploration and recognition}

Mice (WT mice: 12 males and 6 females; Casp $3^{-1-}$ mice: 13 males and 6 females) were habituated to an empty arena $(40 \times 40 \times 35 \mathrm{~cm})$ before the experiment. On day 1 , two identical objects were placed near the opposite corners of the arena, and the mice were free to explore for $15 \mathrm{~min}$. On day 2 , one of the objects from day 1 was replaced with a distinct novel object, and the mice explored for $15 \mathrm{~min}$. The time spent exploring an object was recorded from a camera mounted overhead and was analyzed by an automated tracking program (TopScan, CleverSys). Novel object preference, calculated as [time spent exploring novel object/(novel object + familiar object)] $\times 100$, was analyzed from the first active $1 \mathrm{~min}$ bin.

\section{Contextual fear conditioning}

Experiments were conducted in a chamber with a clear Plexiglas door, three aluminum walls, and a stainless grid floor, housed within a ventilated sound-attenuated box (Med Associates). On day 1, mice (21 WT mice and 13 Casp $3^{-1-}$ mice) were placed in the chamber. After $3.5 \mathrm{~min}$, two sequential $2 \mathrm{~s}$ footshocks of $1.0 \mathrm{~mA}$ were delivered $(2 \mathrm{~min}$ between footshocks). Mice were removed from the chamber $1.5 \mathrm{~min}$ after termination of the second footshock. On day 2, mice were returned to the same chamber for $6 \mathrm{~min}$. Approximately $4 \mathrm{~h}$ later, mice were returned for 3 min to an altered chamber. The grid floor was covered with a smooth Plexiglas plate, and the chamber walls were covered with a curved Plexiglas insert. The house light was turned off, and the chamber was wiped with $1 \%$ acetic acid. Movements were recorded from a camera mounted above the chamber. The percentage of time that a mouse spent freezing was measured by an automated tracking program (Video Freeze, Med Associates), and was analyzed from the first $3 \mathrm{~min}$ (preshock) and the last $1.5 \mathrm{~min}$ (postshock) of the training session on day 1 , and the first $3 \mathrm{~min}$ of the testing sessions in trained or altered context on day 2 .

\section{Rotarod}

Mice (21 WT mice and 13 Casp $3^{-1-}$ mice) were trained to walk continuously on a rotating cylinder $(3.0 \mathrm{~cm}$ diameter) placed $35 \mathrm{~cm}$ above the bench. On days $1-2$, the rod rotated at a fixed speed of $20 \mathrm{rpm}$ over three sessions of four trials each (5-10 min between trials). Each trial lasted for a maximum of $60 \mathrm{~s}$. On day 3 , the mice that were unable to remain on the rod for $60 \mathrm{~s}$ in any of the 12 training trials were subjected to additional training of four trials during which the rod rotated at a fixed speed of 16 $\mathrm{rpm}$. On day 4, all mice were first tested in a single fixed-speed trial (16 
rpm) with a maximum duration of $60 \mathrm{~s}$. Then, mice were tested in a session of three trials ( $1 \mathrm{~h} \mathrm{ITI}$ ), during which the rod gradually accelerated from 4 to $40 \mathrm{rpm}$ over $6 \mathrm{~min}$. The latency to fall was recorded.

\section{Negative geotaxis}

Mice were placed on a textured surface inclined at $35^{\circ}$, facing downward. The latency to turn and reorient upward was recorded.

\section{Wire hang}

Mice were placed on a metal wire lid, and allowed to grasp the wires. Then, the lid was gently inverted and held $20 \mathrm{~cm}$ above the floor. The latency to fall during a $60 \mathrm{~s}$ trial was recorded.

Immunohistochemistry, c-Fos quantification, and statistical analysis

Mice were deeply anesthetized immediately after novel environment exploration, or from undisturbed home cages, and were transcardially perfused with PBS. The brains were removed and drop fixed with $4 \%$ paraformaldehyde in $\mathrm{PBS}$ at $4^{\circ} \mathrm{C}$ for $48 \mathrm{~h}$, and then transferred to $30 \%$ sucrose in $\mathrm{PBS}$ at $4^{\circ} \mathrm{C}$. Coronal floating microtome sections $(35 \mu \mathrm{m})$ were collected and stored in cryoprotectant (30\% glycerol and 30\% ethylene glycol in PBS) at $-20^{\circ} \mathrm{C}$ until further processing. After quenching endogenous peroxidase activity with $3 \% \mathrm{H}_{2} \mathrm{O}_{2}$ in PBS, sections were blocked in PBS containing 5\% goat serum and 0.3\% Triton X-100 for $1 \mathrm{~h}$ at room temperature, subsequently incubated in primary antibody against c-Fos (1:5000; Ab-5, Millipore) overnight at $4^{\circ} \mathrm{C}$, washed in PBS containing $0.1 \%$ Triton X-100, and incubated in biotinylated goat antirabbit antibody (1:500; Vector Laboratories) for $1 \mathrm{~h}$ at room temperature. Immunohistochemical signals were visualized by using standard avidin-biotin/peroxidase methods according to the manufacturer's instructions (Vector Laboratories).

Digital images were acquired using the Olympus Nanozoomer whole slide-imaging system with a $20 \times$ objective and $4096 \times 64$ pixel TDI CCD sensors. Three coronal sections per mouse between -1.46 and -2.54 $\mathrm{mm}$ from bregma were selected for the granular layer of dentate gyrus, three sections between -2.80 and $-3.88 \mathrm{~mm}$ for entorhinal cortex, and four sections between 1.42 and $0.02 \mathrm{~mm}$ for dorsomedial striatum. Equivalent sections were selected blind to genotype and stimulus conditions. Structures were anatomically defined according to The Mouse Brain in Stereotaxic Coordinates (Franklin and Paxinos, 2008). Total areas (in square millimeters) of regions of interest (ROIs) were measured. c-Fos-immunopositive cells within the ROIs were automatically counted using a color threshold and minima-controlled watershed algorithm in Matlab, as described previously (Le Pichon et al., 2013). All image analysis was performed blind to genotype and stimulus conditions.

To determine whether genotype modified the relationship between c-Fos levels in the dentate gyrus and open field score, we fit the following multivariate linear model for each environment:

$\log _{10}($ open field score $)=\beta_{0}+\beta_{1} * \log _{10}(\mathrm{c}-\mathrm{Fos})$

$$
+\beta_{2} * \text { genotype }+\beta_{3} * \log _{10}(\mathrm{c}-\mathrm{Fos}) * \text { genotype. }
$$

We tested the null hypothesis that there is no interaction between c-Fos and genotype.

\section{Immunoblotting and antibodies}

For the detection of protein expression in total cell lysates, cells were lysed in Novex Tris-Glycine SDS sample buffer containing NuPAGE sample reducing agent (Invitrogen). For the detection of protein expression in tissue lysates, hippocampi were homogenized in tissue lysis buffer (50 mм Tris- $\mathrm{HCl}, \mathrm{pH} 7.5,150 \mathrm{~mm} \mathrm{NaCl}, 1 \%$ Triton X-100, 1\% sodium deoxycholate, $0.1 \%$ SDS, $8 \mathrm{M}$ urea, $5 \mathrm{~mm}$ EDTA, supplemented with $1 \mathrm{~mm}$ DTT, $1 \mathrm{~mm}$ phenylmethylsulfonyl fluoride, and protease and phosphatase inhibitor cocktails), by using TissueLyser II (Qiagen). For experienced mice, hippocampal homogenates were collected 1 month after the last behavior testing ended. Homogenates were subsequently cleared via centrifugation at $20,000 \times g$ for $30 \mathrm{~min}$. Protein concentration of the supernatant was measured by using BCA Protein Assay Kit (Pierce). Lysates with equal amounts of total proteins were electrophoresed through Novex Tris-Glycine gels or NuPAGE Bis-Tris gels, transferred to nitrocellulose membranes, and subjected to immunoblot analysis. The blocking of membranes and subsequent antibody incubations were performed by using Odyssey blocking buffer (LI-COR Biosciences) according to the manufacturer's instructions. Primary antibodies against GluAl (C3T, Millipore), GluA2 (MAB397, Millipore), PSD95 (ab2723, Abcam), PSD95-pS295 (ab16495, Abcam), GluN1/NR1 (ab109182, Abcam), GluN2A/NR2A (NB300-105, Novus), GluN2B/NR2B (N59/20, NeuroMab), mGluR5 (AB5675, Millipore), actin (BD Biosciences), GAPDH (Abcam), and caspase-3 (CST9662, Cell Signaling Technology) were purchased from commercial sources. The IRDye 800CWconjugated and IRDye 680-conjugated secondary antibodies were obtained from LI-COR Biosciences. Immunoblot signals were visualized by the Odyssey infrared imaging system, and quantified by ODYSSEY application software (version 3.0; LI-COR Biosciences).

\section{Dissociated neuron culture and whole-cell patch recording}

Hippocampal neuron cultures were prepared and cultured from embryonic day 15-16 mouse embryos. Cells were dissociated by using $20 \mathrm{U} / \mathrm{ml}$ papain (Worthington), and $470-530$ cells $/ \mathrm{mm}^{2}$ were plated on $15 \mathrm{~mm}$ coverslips (Carolina Biological) coated with $0.5 \mathrm{mg} / \mathrm{ml}$ poly-D-lysine (P7886, Sigma) and $2.5 \mu \mathrm{g} / \mathrm{ml}$ laminin (Invitrogen). Dissociated cells were allowed to recover overnight in DMEM in the presence of $10 \%$ fetal bovine serum, 2 mm L-glutamine, and $0.9 \%$ glucose, and subsequently maintained in Neurobasal medium (Invitrogen) supplemented with $2 \%$ B27 (Invitrogen) and 1\% GlutaMAX (Invitrogen).

Whole-cell voltage-clamp recordings of cultured hippocampal neurons (20-23 DIV) were performed $\sim 24 \mathrm{~h}$ after drug treatment. $\mathrm{Z}$-DEVD-FMK was refreshed again $\sim 12 \mathrm{~h}$ before recording. Miniature EPSCs (mEPSCs) were recorded at a holding membrane potential of -70 $\mathrm{mV}$. The recording solution was oxygenated artificial cerebrospinal fluid (ACSF) containing $127 \mathrm{~mm} \mathrm{NaCl}, 2.5 \mathrm{~mm} \mathrm{KCl,} 25 \mathrm{~mm} \mathrm{NaHCO}_{3}, 1.25 \mathrm{~mm}$ $\mathrm{NaH}_{2} \mathrm{PO}_{4}, 25 \mathrm{~mm}$ glucose, $1.3 \mathrm{~mm} \mathrm{MgSO}_{4}$, and $2.5 \mathrm{~mm} \mathrm{CaCl}_{2}$, with 100 $\mu \mathrm{M}$ picrotoxin and $1 \mu \mathrm{M}$ tetrodotoxin. The pipette solution contained the following: $115 \mathrm{~mm}$ Cs methanesulfonate, $20 \mathrm{~mm} \mathrm{CsCl}, 10 \mathrm{~mm}$ HEPES, $2.5 \mathrm{~mm} \mathrm{MgCl}_{2}, 4 \mathrm{~mm} \mathrm{Na}$ ATP, 0.4 mM Na 3 GTP, $10 \mathrm{~mm} \mathrm{Na}$ phosphocreatine, and 0.6 mM EGTA, pH 7.25. Neurons from three to four independent batches of cultures were recorded for each condition. mEPSCs were analyzed using Mini Analysis (Synpatosoft).

\section{Results}

Reduced attention control, increased impulsive behavior and hyperactivity in Casp $3^{-/-}$mice

In a broad investigation of behavior in multiple domains, we determined that Casp3 ${ }^{-1-}$ mice had no deficits in neurological reflexes, motor function and learning, or contextual conditioning, but exhibited increased locomotor activity in an open field (Table 1). We then focused on examining self-regulatory behaviors, especially attention control, in the five-choice serial reaction time task (5-CSRTT), a visuospatial discrimination task that challenges attention processes (Robbins, 2002; Lustig et al., 2013). The task requires the animals to detect a brief light stimulus presented pseudorandomly in one of five holes, and respond by nose poking in the correct hole to receive a food reward. Mice were trained progressively to reach defined performance criteria at each of eight stages. Overall, Casp $3^{-1-}$ mice acquired the task quickly, even outperforming WT mice during early training (Fig. $1 A, E, F)$. During the training phase, all mice learned to respond accurately (Fig. $1 B$ ). Initially, Casp $3^{-1-}$ mice made more unrewarded premature responses during the ITI (lasting $5 \mathrm{~s}$ ) than their WT littermates, but over time both Casp $3^{-1-}$ and WT mice learned to suppress premature responses equally well (Fig. 1C). The training phase was concluded when mice were able to respond accurately to a stimulus lasting $2 \mathrm{~s}$, at which point Casp $3^{-1-}$ and WT mice showed comparable response accuracy, latency to making correct responses, omissions, premature responses, and latency to collecting rewards (Fig. $1 B, C, E-G$ ). Al- 
Table 1. Effects of genetic knockout of caspase-3 on neurological reflexes, spontaneous locomotor activity, motor function and learning, and contextual conditioning

\begin{tabular}{|c|c|c|c|}
\hline Task and measure & WT mice & Casp3 $^{-1-}$ mice & $p$ value \\
\hline Mice showing eye blink reflex & $21 / 21$ & $13 / 13$ & \\
\hline Mice showing vibrissae reflex & $21 / 21$ & $13 / 13$ & \\
\hline Mice showing posture reflex & $21 / 21$ & $13 / 13$ & \\
\hline Wire hang, latency to fall (s) & $48.62 \pm 3.785(n=21)$ & $41.69 \pm 5.510(n=13)$ & 0.2923 \\
\hline Tail suspension test, mice showing limb clasping & $0 / 21$ & $0 / 12$ & \\
\hline Open field test, total beam breaks $(1 \mathrm{~h})$ & $4389 \pm 346.1(n=21)$ & $10026 \pm 1720(n=13)$ & $0.0004^{*}$ \\
\hline
\end{tabular}

Data are presented as the number of mice showed the presence of the reflexes or limb clasping/total number of mice tested or the mean \pm SEM by ANOVA, unless otherwise indicated. One Casp $3{ }^{-1}-$ mouse had a curly tail and was excluded from the tail suspension test. The context discrimination index is calculated as [freeze in trained context/(trained + altered context)]. ${ }^{*} p<0.001$.

though they showed normal acquisition in the 5-CSRTT, Casp $3^{-1-}$ mice exhibited persistently higher locomotor activity than their WT littermates in this task (Fig. 1D).

After stable baseline performance in the 5-CSRTT was maintained for 6 days, several task parameters were modified to challenge attention. First, we increased the attention load of the task by reducing the light stimulus duration. Response accuracy in WT mice stayed at $\sim 80 \%$, but in Casp $3^{-1-}$ mice, accuracy declined to $\sim 63 \%$ at the shortest stimulus duration of $0.3 \mathrm{~s}$ (Fig. $2 \mathrm{~A}$, left). In addition, Casp $3^{-/-}$mice made significantly more premature responses than WT mice, suggesting that Casp $3^{-1-}$ mice may revert to impulsive behavior when challenged with an unpredictable increase in attention load (Fig. 2A, right). Further evidence of enhanced impulsivity in Casp $3^{-1-}$ mice was seen when Casp $3^{-1-}$ mice made more premature responses than WT mice during prolonged ITIs (6 s; Fig. 2B; Robbins, 2002). Next, we assessed distractibility and inhibitory control in selective attention by introducing visual distraction in the form of brief and weak light stimuli presented in the additional four inactive apertures simultaneously, and pseudorandomly at $0.3,2.5$, or $4.3 \mathrm{~s}$ following the onset of ITI. The presentation of unpredictable visual distraction at $2.5 \mathrm{~s}$ after ITI onset had the most disruptive effect on the ability of the animal to withhold responses until the task-relevant stimulus was presented (Fig. 2C). Casp3 ${ }^{-1-}$ mice responded prematurely 1.8 times more frequently than WT mice under this condition, and 5 times more often than WT mice when visual distraction was presented at $0.3 \mathrm{~s}$ after ITI onset (Fig. $2 C)$. Finally, we selected a distractor time point that affected premature responding in both genotypes similarly (4.3 $\mathrm{s}$ after ITI onset) to compare the effect of visual distraction on response accuracy. Response accuracy fell to nearly $66 \%$ in both genotypes as the session started (Fig. 2D). Interestingly, with repeated trials, WT mice were able to improve to $80 \%$ accuracy, whereas Casp3 $3^{-1-}$ mice continued to perform poorly over time (Fig. 2D), suggesting an impaired ability to focus selective attention on the task-relevant stimulus. Together, these findings indicate that Casp $3^{-1-}$ mice have impaired attention processes, reduced inhibitory control, and hyperlocomotion-behaviors that are reminiscent of the core ADHD-like symptomatology.

\section{Reduced behavioral flexibility in Casp $3^{-/-}$mice}

As reduced ability to adjust behavior in response to changed circumstances is commonly seen in certain neurodevelopmental disorders, including ADHD (Jurado and Rosselli, 2007; Marzocchi et al., 2008), we assessed behavioral flexibility of Casp3 ${ }^{-1-}$ mice in spatial reversal learning in the Morris water maze (MWM) task. Mice were first trained to locate a submerged platform using distal spatial cues. Casp $3^{-1-}$ mice and WT littermates acquired the task at similar rates (Fig. $3 A$ ) and showed a similar preference for searching in the correct location during a probe trial (Fig. $3 B, C$ ), demonstrating normal spatial learning and memory abilities. When the platform was moved to the opposite quadrant of the pool for reversal learning, WT mice learned the new platform location within four trials, indicating rapid adaptation to the new goal (Fig. $3 D$ ). In comparison, Casp $3^{-/-}$mice showed slower reversal learning (Fig. 3D) and searched over the old platform location more often (Fig. $3 E$ ), indicating inefficient suppression of previously learned responses and hence impaired cognitive flexibility. The poor reversal learning is unlikely to be due to motor or motivational differences, since both genotype groups had similar swimming speeds during the task (Fig. $3 F$ ).

Next, we examined Casp3 ${ }^{-1-}$ mice in nonspatial reversal learning in a mouse version of an attentional set shifting task (ASST). This two-choice discrimination task for odor or tactile stimuli requires the animals to dig for a food reward buried in one of the two digging bowls. The correct choice is indicated either by a unique odor or a digging medium of unique texture. During the initial simple discrimination (SD) stage, mice were trained to discriminate between two bowls that differed along one of the two stimulus modalities (i.e., odor or digging medium) and to dig only in the bowl with the rewarded stimulus (e.g., cinnamon or onion for odor; paper bedding or plastic beads for digging media). Both Casp $3^{-I-}$ and WT mice learned to reliably dig in the rewarded bowl to the criterion of six consecutive correct trials within $30 \mathrm{~min}$ (data not shown). In the following CD stage, two bowls differed along both of the stimulus modalities (i.e., odor and digging medium), but the rewarded stimulus remained unchanged. Both Casp3 ${ }^{-1-}$ and WT mice readily learned to ignore the newly added modality of odor or tactile stimuli and, on average, reached the task criterion within a minimum of six trials while making almost no errors (Fig. $3 G$, left, right). When the rewarded and unrewarded stimuli of the same modality were switched in the CDR stage, both genotype groups made approximately two errors and spent approximately four more trials on average to learn to reliably dig in the rewarded bowl (Fig. 3G, left, right), indicating comparable reversal learning of nonspatial information between Casp3 $3^{-1-}$ and WT mice.

\section{Enhanced reactivity and reduced habituation to visuospatial} novelty in Casp $3^{-/-}$mice

While Casp3 $3^{-1-}$ mice can learn quickly in the 5-CSRTT and MWM task, their cognitive performance degrades once new information is incorporated. To determine whether responses to novel stimuli are altered in Casp $3^{-1-}$ mice, we first examined their exploratory drive in a novel context. Casp $3^{-1-}$ mice displayed persistently higher locomotion than their WT littermates 
A

Days to criteria

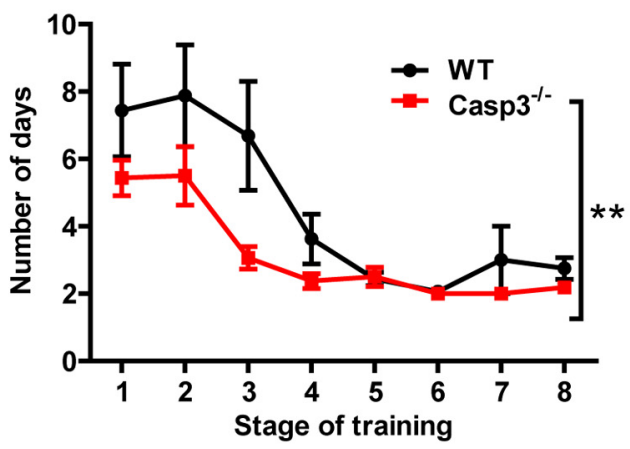

C

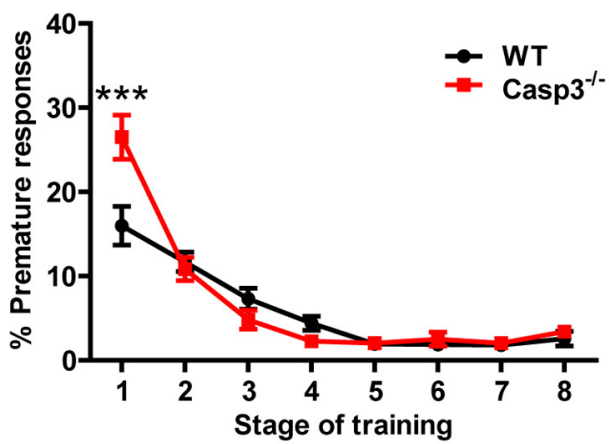

E

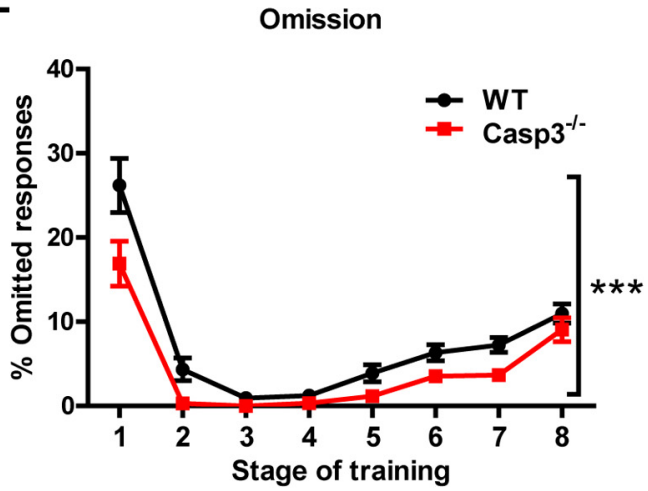

G

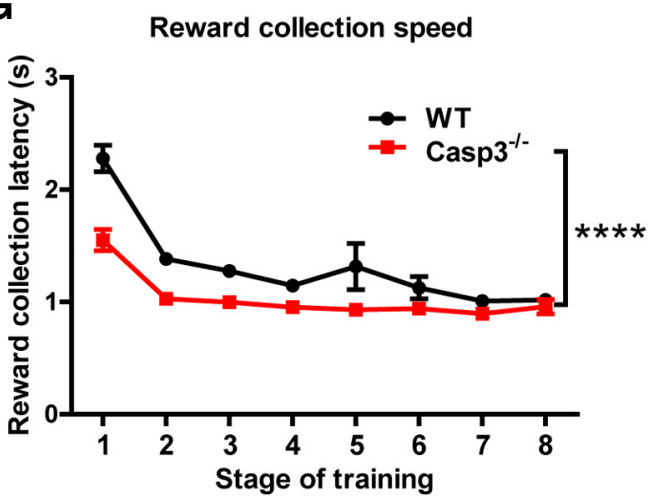

B

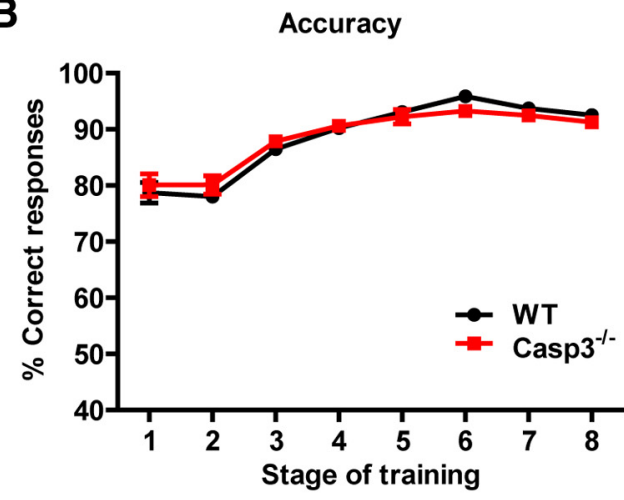

D

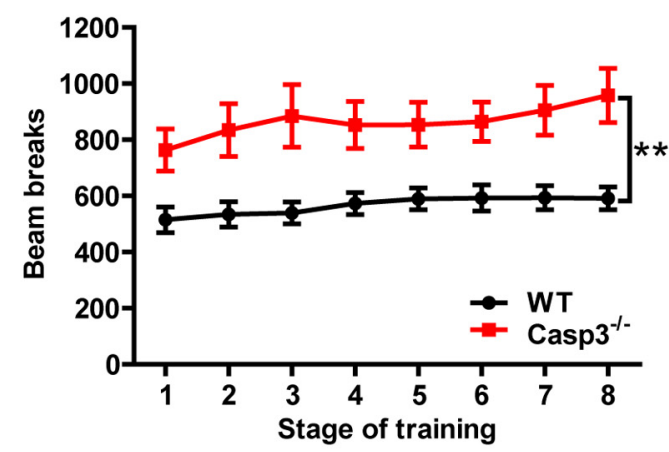

F

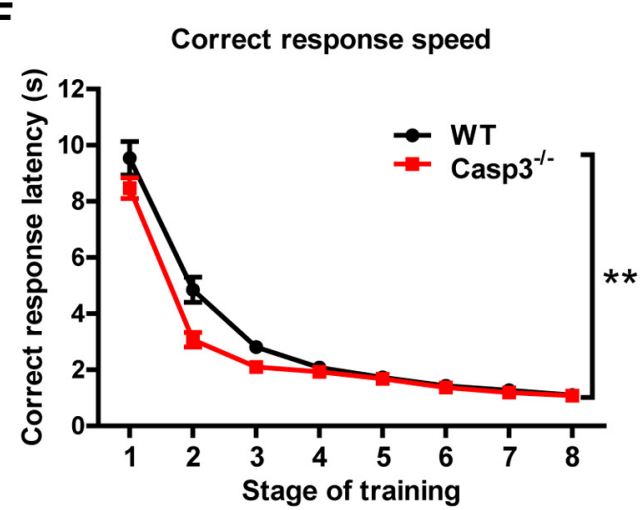

Figure 1. Casp3 $3^{-1-}$ mice have normal learning of 5-CSRTT. Performance and motivational behavior upon completion of training phases show no genotype difference. $A-G, A$ At each training stage during acquisition, graphs show the number of days taken to reach criteria $(\boldsymbol{A})$; average response accuracy per day $(\boldsymbol{B} ; \boldsymbol{p}>0.05)$; average daily percentage of premature responses made during the ITI (C); average locomotor activity, measured by beam breaks $(\boldsymbol{D})$; average daily percentage of omitted responses $(\boldsymbol{E})$; average daily latency to perform correct responses $(\boldsymbol{F})$; and average daily latency to collect a food reward $(\boldsymbol{G})$. Points represent the mean \pm SEM for 16 mice per genotype in $A-G .{ }^{*} p<0.05,{ }^{* *} p<0.01,{ }^{* * *} p<0.001,{ }^{* * * *} p<0.0001$ for genotype effect, by repeated measures two-way ANOVA $(A, B, D-G)$ and by Bonferroni post-test $(C)$. 
A

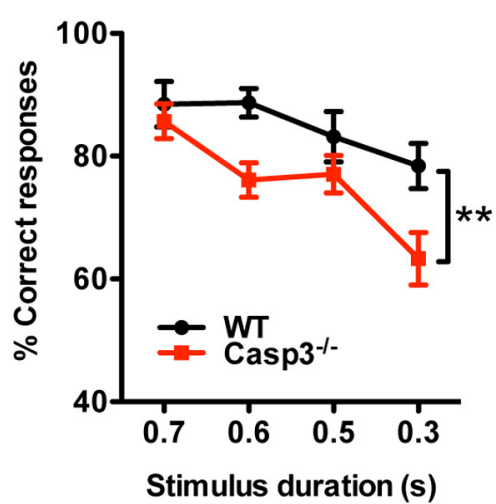

C

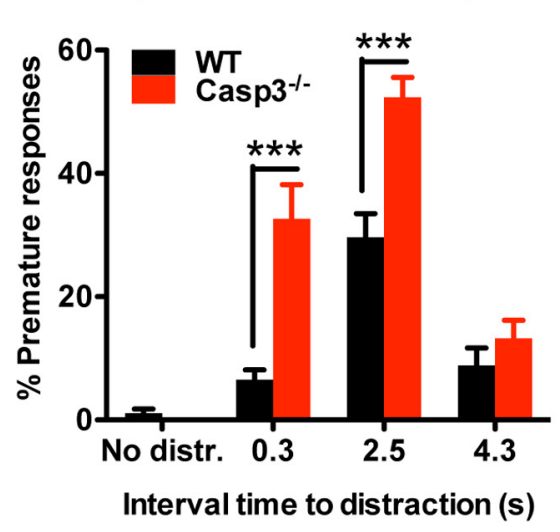

\section{Premature response (visual distraction during ITI)}

Premature response

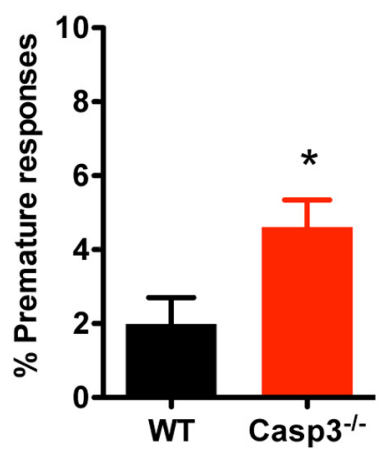

D
B

\section{Premature response (longer ITI: 6 s)}

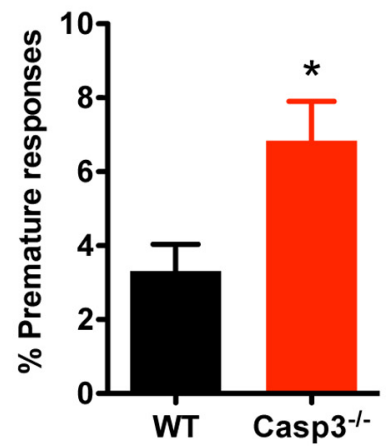

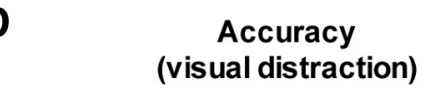

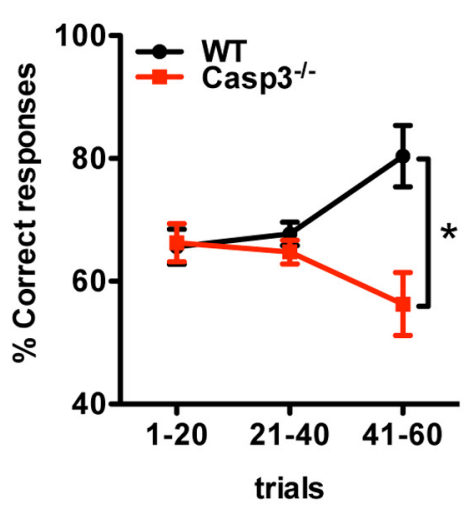

Figure 2. Casp $3^{-1-}$ mice exhibit impaired attention processes and reduced inhibitory control when further challenged in the 5-CSRTT. A-D, During testing, graphs show the effects of stimulus duration on response accuracy $(\boldsymbol{A}$, left) or on premature responses $(\boldsymbol{A}$, right); effects of increasing the ITI on premature responses $(\boldsymbol{B})$; effects of visual distraction on premature responses $(\boldsymbol{C})$; and effects of visual distraction on response accuracy $(\boldsymbol{D})$, analyzed in 20 -trial bins $\left(p<0.05\right.$ for genotype $\times$ trial interaction). Points represent the mean \pm SEM for 15 WT and 16 Casp3 ${ }^{-I-}$ mice in $\boldsymbol{A} ; 15$ WT and 15 Casp3 $^{-1-}$ mice in $\boldsymbol{B} ; 9$ WT and 15 Casp3 ${ }^{-1-}$ mice in $\boldsymbol{C}$ and $\boldsymbol{D} .{ }^{*} p<0.05,{ }^{* *} p<0.01,{ }^{* * *} p<0.001$ for genotype effect, by repeated measures two-way ANOVA $(\boldsymbol{A}$, left, $\boldsymbol{D})$; by ANOVA $(A$, right, $B, C$.

in a novel open field (Fig. 4A). During an hour of free exploration, a progressive decline in locomotion was seen in WT mice, reflecting habituation to the environment (Fig. $4 A$ ). This decrease can be expressed for each individual animal by an habituation index, which was calculated as the ratio of its locomotion in each $10 \mathrm{~min}$ bin to the locomotion in the first $10 \mathrm{~min}$ bin (Fig. $4 B)$. The habituation index in WT mice fell to $\sim 0.5$ after an hour in the open field, but in Casp $3^{-1-}$ mice the index stayed at $\sim 1$ on average (Fig. $4 B$ ). Similarly, when the mice were returned to the same open field repeatedly after $3 \mathrm{~d}$ intervals, the WT mice showed diminishing locomotion with each visit, reflecting habituation, whereas Casp3 ${ }^{-1-}$ mice did not (Fig. 4C).

Next, we examined the animals' responses to novel objects. A series of different novel objects were presented sequentially over seven consecutive trials (Fig. 4D). WT mice explored a novel object during trial 1 , but spent less time exploring exact duplicates of the object during trials 2 and 3 (habituation; Fig. 4D). When a distinct object was introduced during trial 4 , exploration time rebounded (dishabituation) and subsequently decreased during trials 5 and 6 when the same second object was repeated (Fig. 4D). In contrast, Casp $3^{-1-}$ mice showed sustained exploration time in most trials (Fig. $4 D$ ). Although Casp $3^{-1-}$ mice explored significantly more than WT mice during trial $1(p<0.05)$, the habituation index showed that WT mice explored $\sim 75 \%$ less on average in trial 3 relative to trial 1 ; whereas, Casp $3^{-1-}$ mice explored only $\sim 25 \%$ less, indicating diminished habituation to the objects (Fig. $4 E$ ). Lastly, to determine whether the abnormal habituation is due to deficits in object discrimination or recall, we examined visual recognition memory in a novel object recognition test. During the training phase, Casp $3^{-1-}$ mice spent significantly more time exploring a novel object than WT mice, which is consistent with the increased exploratory drive observed during the habituation task (Fig. 4F, day 1). During the retention test, both genotype groups showed a clear preference for exploring a newly introduced novel object over the familiar one (Fig. $4 F$, day 2), demonstrating intact object recognition and memory.

Enhanced dentate gyrus activation in Casp $3^{-/-}$mice during prolonged exposure to novel environment

To look for brain activity correlates of the heightened behavioral reactivity to novel stimuli in Casp $3^{-1-}$ mice, we monitored induction in the brain of the immediate early gene c-fos, a marker of neuronal activation. Low levels of c-Fos immunostaining were observed in animals left undisturbed in home cages, but prominent expression of c-Fos protein was detected in multiple brain 
A

Acquisition (Day 1-5)

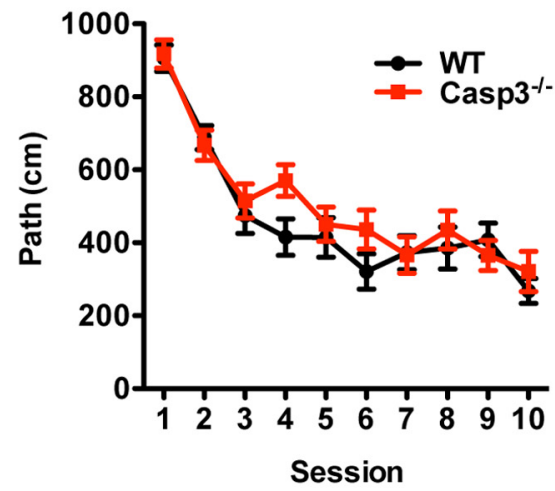

D

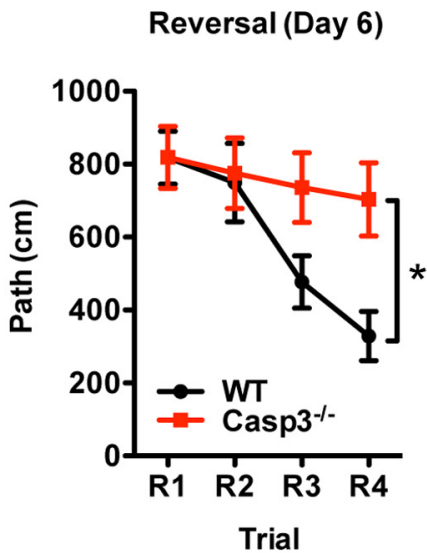

G Trials to criterion

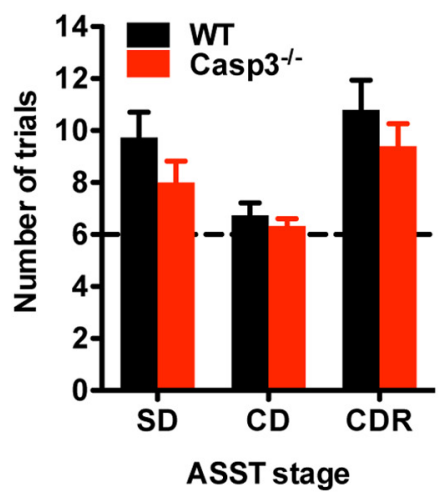

B

Probe trial (Day 6)

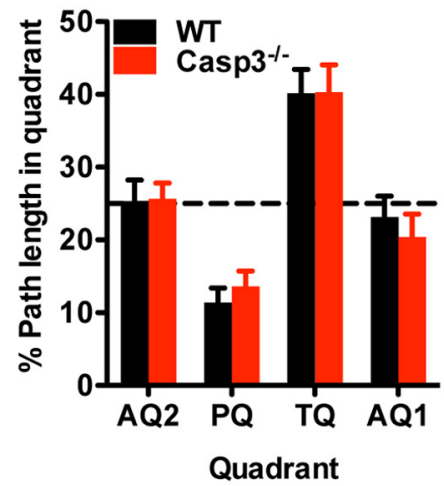

$\mathbf{E}$
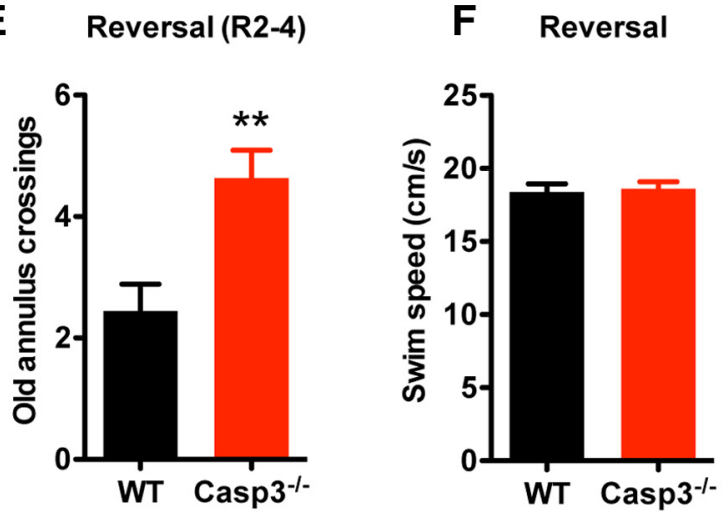

F Reversal

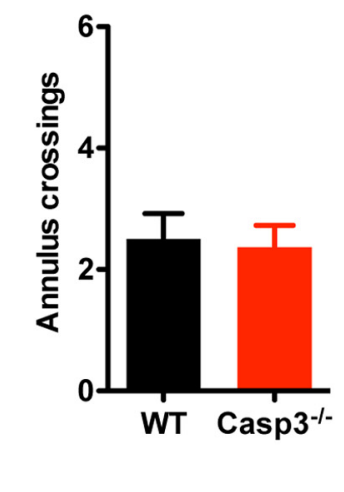

C Probe trial (Day 6)

Errors to criterion

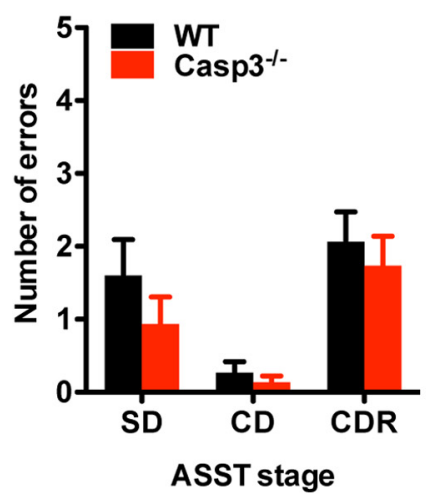

Figure 3. Casp $3^{-1-}$ mice have normal learning of the MWM task, but exhibit reduced behavioral flexibility. $A$, Distance to the hidden platform was analyzed across three-trial training sessions $(p>0.05)$. $\boldsymbol{B}$, Percentage of distance traveled in the target quadrant (TQ), the opposite quadrant (PQ), and the adjacent quadrants (AQ1 and AQ2) during probe trial $(p>0.05$ vs WT mice). C, Number of crossings made over the platform location during the probe trial ( $p>0.05$ vs WT mice). $D$, Distance of swim path to the new platform in trials R1-R4 during the reversal phase. $\boldsymbol{E}$, Total number of crossings made over the old platform location in trials R2-R4. $\boldsymbol{F}$, Average swim speed during the reversal phase $(p>0.05)$. $\mathbf{G}$, Casp3 ${ }^{-1-}$ mice exhibit normal reversal learning in the ASST. Graphs show the number of trials taken to reach criterion ( $G$, left) and the number of errors made before reaching criterion $(\mathbf{G}$, right). Graphs show the mean \pm SEM for 18 WT and 19 Casp3 $^{-1-}$ mice in $\boldsymbol{A}-\boldsymbol{F}$, and 15 WT and 15 Casp $3 ~^{-1-}$ mice in $\mathbf{G}$. ${ }^{*} p<0.05,{ }^{* *} p<0.01$ for genotype effect, by repeated-measures two-way $\operatorname{ANOVA}(\boldsymbol{A}, \boldsymbol{D})$ and by ANOVA $(\boldsymbol{B}, \boldsymbol{C}, \boldsymbol{E}-\boldsymbol{G})$.

regions after a $2 \mathrm{~h}$ exposure to a novel environment. There were significantly more c-Fos-immunopositive cells in the dentate gyrus of Casp $3^{-1-}$ mice than in their WT littermates (Fig. $5 A, B$ ). The dentate gyrus of the hippocampus is involved in novelty exploration behavior (Kemp and Manahan-Vaughan, 2008; Saab et al., 2009). c-Fos levels did not differ between WT and Casp $3^{-1-}$ mice in the entorhinal cortex, a brain region that re- ceives processed input from multiple sensory modalities, or in the striatum, a region that regulates locomotor behaviors (Fig. $5 A, B)$. Further analysis revealed a significant genotype effect on the relationship between $c$-Fos levels in the dentate gyrus and exploratory activity in the novel open field ( $p<0.001$; Fig. $5 C$ ), which was positively correlated in Casp $3^{-1-}$ mice and negatively correlated in WT mice. 
A

Locomotion (1 h)

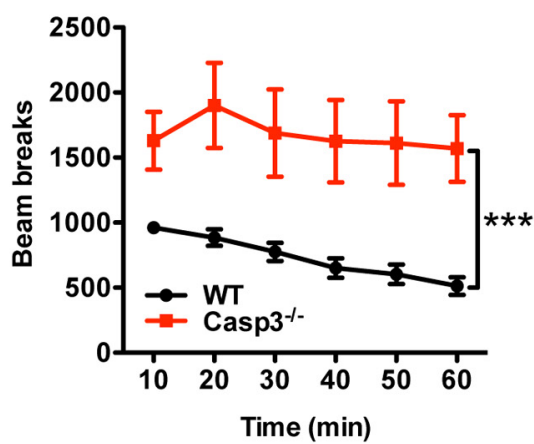

B

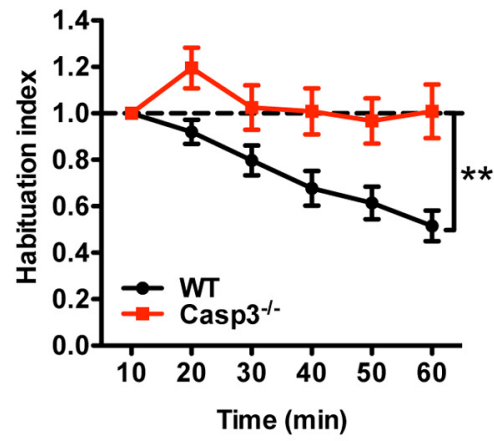

C

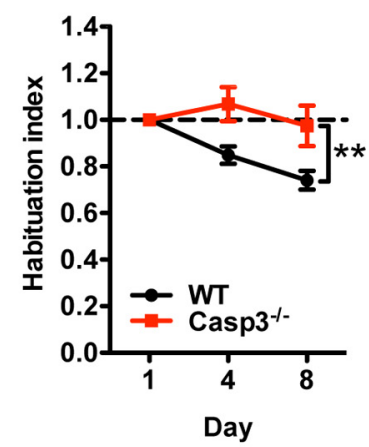

D

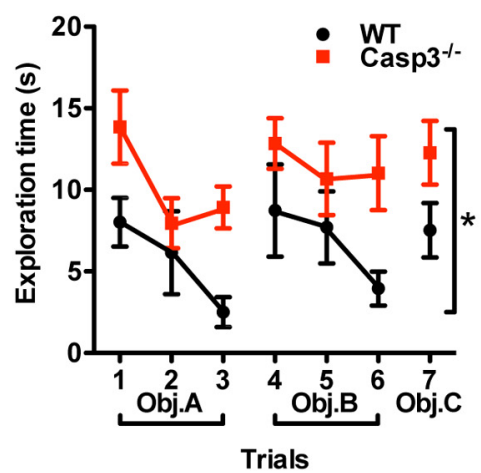

E

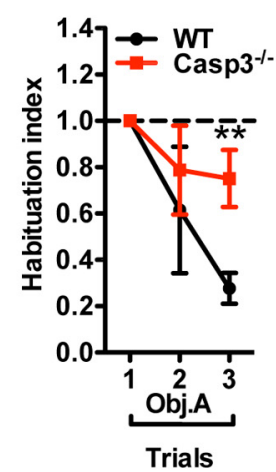

$\mathbf{F}$

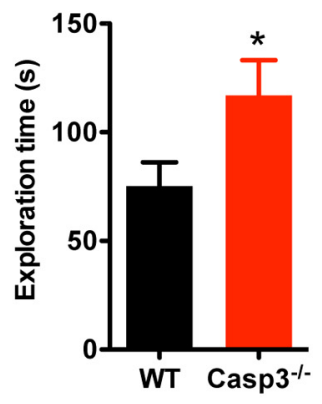

Day 2

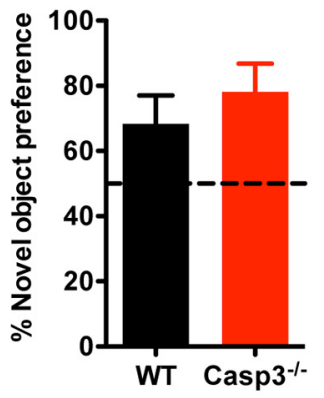

Figure 4. Effects of novel stimuli over time on arousal, reactivity, and habituation in Casp $3^{-1-}$ mice. $\boldsymbol{A}, \boldsymbol{B}$, Graphs show locomotion over $1 \mathrm{~h}$ in a novel open field, analyzed in $10 \mathrm{~min}$ bins $(\boldsymbol{A})$ and the within-session habituation index $(\boldsymbol{B}), p<0.05$ for genotype $\times$ time interaction. $\boldsymbol{C}$, Habituation index across days 1,4 , and 8 in an open field, calculated as [(locomotion on each day)/(locomotion on day 1)], $p<0.05$ for genotype $\times$ time interaction. $\boldsymbol{D}, \boldsymbol{E}$, Graphs show the time spent exploring novel objects over seven trials $(\boldsymbol{D})$ and the habituation index $(\boldsymbol{E})$, calculated as [(exploration time in each trial)/(exploration time in trial 1)]. $\boldsymbol{F}$, Left, Time spent exploring novel objects during training. Right, Preference for new object, calculated as [(time spent exploring the new object)/(total time spent exploring the new and the trained objects) $] \times 100 \%(p>0.05)$. Plots show the mean \pm SEM for 21 WT and 13 Casp3 ${ }^{-I-}$ mice in $\boldsymbol{A}-\boldsymbol{C} ;$ and 18 WT and 19 Casp3 ${ }^{-I-}$ mice in $\boldsymbol{D}-\boldsymbol{F}$. ${ }^{*} p<$ $0.05,{ }^{* *} p<0.01,{ }^{* * *} p<0.001$ for genotype effect, by repeated-measures two-way ANOVA $(\boldsymbol{A}-\boldsymbol{D})$ and ANOVA $(\boldsymbol{E}, \boldsymbol{F}) .0$ bj., 0 bject.

Caspase-3 deficiency impairs homeostatic synaptic scaling induced by chronic elevation in network activity

Homeostatic adaptation of neural activity has been documented in the CNS and peripheral nervous system following perturbations to activity (Davis, 2006). Homeostatic synaptic plasticity, such as synaptic scaling, can be evoked to keep neuronal firing rates within a suitable range for optimal information processing (Turrigiano, 2012). Failure to maintain synaptic homeostasis has been implicated in a number of neuropsychiatric disorders (Dickman and Davis, 2009; Soden and Chen, 2010; Toro et al., 2010; Qiu et al., 2012). Since weakening of synaptic strength has been shown to accompany repeated exposures to novel stimuli (Jakkamsetti et al., 2013), we asked whether caspase-3 deficiency impairs downscaling of synaptic strength during prolonged elevation of network activity. Dissociated hippocampal neurons in culture were treated with bicuculline ( $40 \mu \mathrm{M}$, for $24 \mathrm{~h}$ ), an antagonist of $\mathrm{GABA}_{\mathrm{A}}$ receptors, to chronically increase firing rates, a commonly used approach to induce homeostatic synaptic downscaling (Turrigiano et al., 1998). The amplitude of mEPSCs in WT neurons fell by $\sim 20-25 \%$ in response to bicuculline treatment, whereas in Casp $3^{-1-}$ neurons it remained unchanged (Fig. $6 A$ ), indicating impaired homeostatic downscaling. Moreover, WT neurons pretreated with a caspase- 3 inhibitor (Z-DEVD-FMK) failed to show a decrease in mEPSC amplitude following bicuculline treatment (Fig. 6B). As homeostatic downscaling in cultured neurons can be accompanied by a decrease in total protein levels of AMPA receptor subunits GluA1 and GluA2 (Fu et al.,
2011; Qiu et al., 2012), we monitored steady-state levels of AMPA receptors upon chronic repetitive elevation of network activity. GluA1 and GluA2 protein levels declined progressively in cultured WT hippocampal neurons subjected to a $3 \mathrm{~h}$ bicuculline treatment daily for $1 \mathrm{~d}$ or 3 consecutive days (Fig. 6C, top panels). Repeated bicuculline treatment, however, did not suppress GluA1 and GluA2 expression in Casp $3^{-1-}$ neurons (Fig. 6C, bottom panels).

Differential modulation of hippocampal GluA1 and GluA2 expression in Casp $3^{-/-}$mice repeatedly challenged with novel behavioral testing

To look for in vivo molecular correlates of sustained arousal and reduced habituation in Casp $3^{-/-}$mice subject to repeated novel stimuli, we measured expression of AMPA receptors in hippocampus. Since it has been shown that exploratory drive wanes in experienced mice after certain behavioral tests (Võikar et al., 2004), we examined "experienced" mice that had been subjected to a number of behavioral tests (physical examinations, and open field, rotarod, MWM, and contextual conditioning tasks), versus age-matched "naive" mice that were housed under standard conditions without additional handling or behavioral testing. Consistent with previous studies (Li et al., 2010), no genotype differences were observed in total protein levels of AMPA receptor subunits GluA1 and GluA2 in the hippocampus of the naive mice (Fig. 7A). In the experienced mice, however, the hippocampus of Casp $3^{-1-}$ mice had total protein levels of GluA1 and 
A
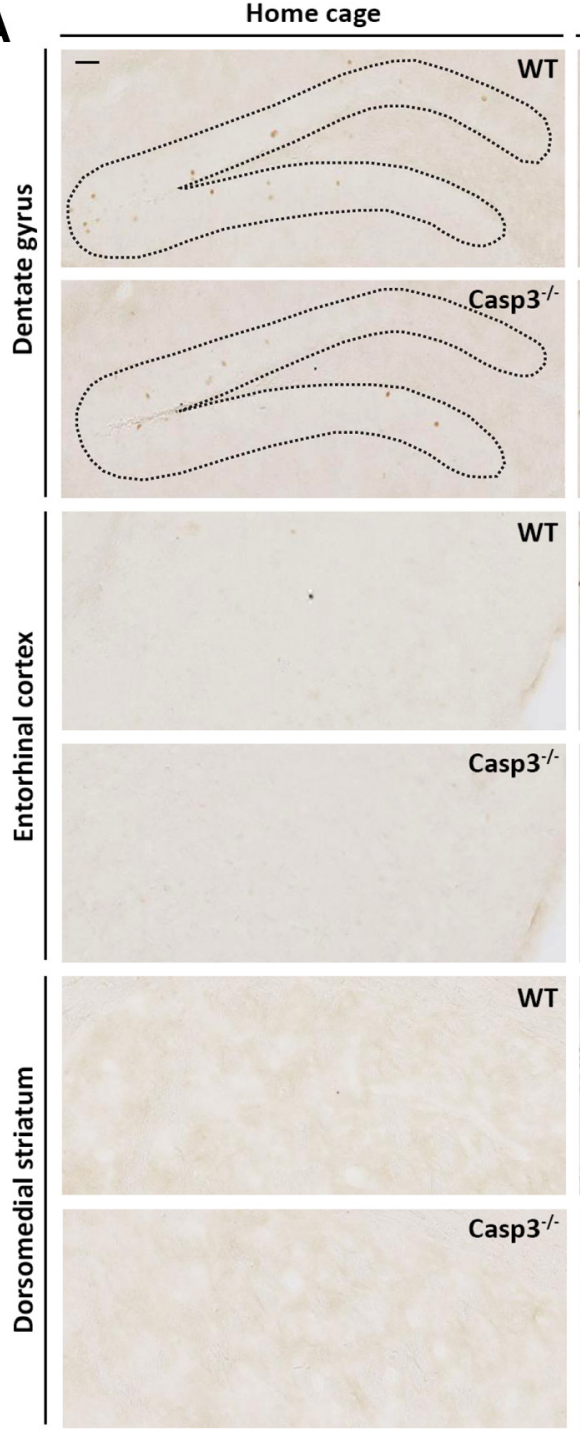

B

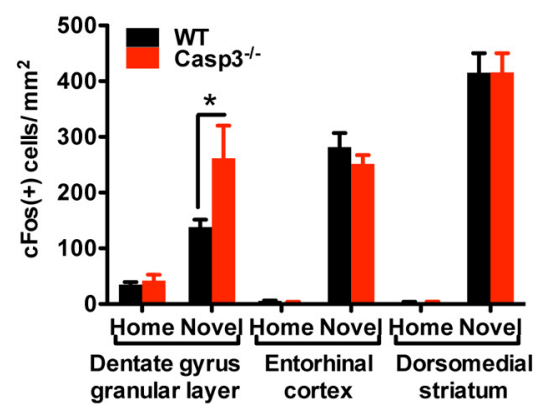

Novel environment
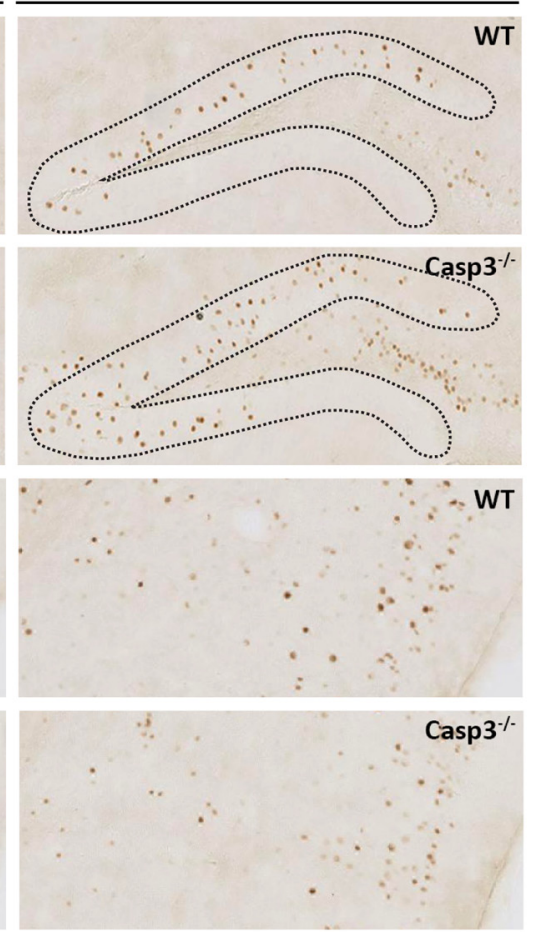

WT
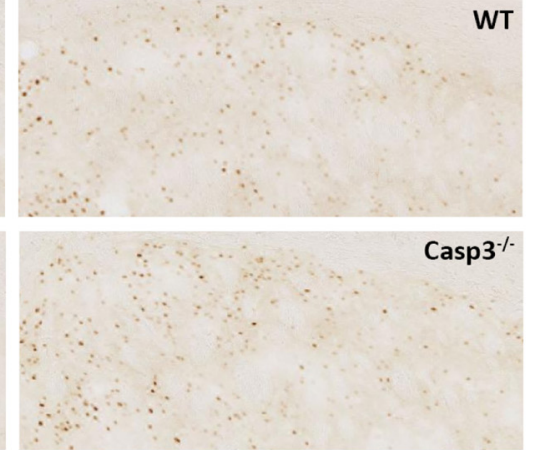

C

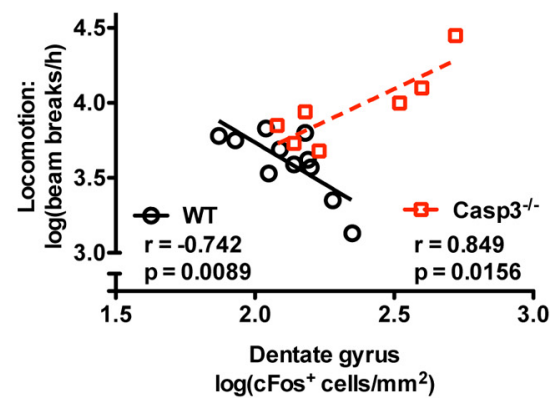

Figure 5. Effects of novel stimuli on dentate gyrus activation in Casp $3^{-/-}$mice. $\boldsymbol{A}$, Representative immunohistochemical signals for c-Fos proteins in dentate gyrus, entorhinal cortex, and dorsomedial striatum. Scale bar, $50 \mu \mathrm{m}$. B, Quantification of c-Fos induction, calculated as [(total number of c-Fos-immunopositive cells)/(area of region of interest)]. C, Correlation between c-Fos induction in dentate gyrus and locomotion in a novel environment. Plots show the mean \pm SEM for 11 WT (Novel), 7 Casp3 $^{-1-}$ (Novel), 10 WT (Home), and 5 Casp3 ${ }^{-1-}$ (Home) mice in $\boldsymbol{B} .{ }^{*} p<0.05$ for genotype effect, by ANOVA.

GluA2 that were 10-20\% higher than their WT littermates (Fig. $7 B)$, indicating that caspase-3 deficiency may interact with repeated behavioral challenges to disrupt homeostasis of AMPA receptor expression. There was no genotype difference in the hippocampal expression of the postsynaptic scaffold protein PSD-95, or in phosphorylation of PSD-95 at Ser295 (Fig. 7B), a post-translational modification that promotes synaptic accumulation of PSD-95. We also found no genotype differences in the hippocampal protein levels of NMDA receptor subunits GluN1, GluN2A, and GluN2B, or in type I mGluR5 (Fig. 7B). Further analysis revealed a significant positive correlation only in Casp3 $3^{-1-}$ mice between hippocampal GluA1 or GluA2 expression and the habituation index of the animal in a novel open field (high habituation index reflects low habituation capacity; Fig. 7C).

\section{Discussion}

While preserving multiple learning and memory capabilities, Casp3 $3^{-1-}$ mice in the C57BL/6 background exhibit behavior traits that bear a striking resemblance to the triad of core symptoms of ADHD (attention deficit, hyperactivity, and impulsivity; Figs. $1 D, 2)$. This set of symptoms is not unique to $\mathrm{ADHD}$, and the underlying etiological factors and heterogeneity are poorly understood (Bari and Robbins, 2011; Fernando and Robbins, 2011). Of note, Casp $3^{-1-}$ mice remained hyperactive when treated with psychostimulant drugs, such as amphetamine, a commonly prescribed medication for ADHD (S.-C. Lo., K. Scearce-Levie, and M. Sheng, unpublished observations). Thus caspase-3 deficiency "simulates" an ADHD-like behavior state, but it does not necessarily model all aspects of clinical ADHD, as typically presented. Indeed, ADHD is associated with, though not defined by, a broader range of cognitive impairments, including disrupted habituation, sensory modulation, and executive functions (Jansiewicz et al., 2004; Marzocchi et al., 2008; Ghanizadeh, 2011). Emerging literature suggests that multiple cognitive deficits associated with ADHD could be traced to impairment in fundamental selfregulatory mechanisms, including adaptive control (Shiels and Hawk, 2010). Adaptive control is the ability to flexibly configure competing information between prediction and perception, and to adjust attentional efforts for behaviorally relevant stimuli (Botvinick et al., 2001). This idea is in keeping with our finding that such adaptability deficits are present in Casp3 ${ }^{-1-}$ mice, as evidenced by their sudden drop in performance upon change of task rules in the MWM task and 5-CSRTT. It is remarkable that several rodent models with disrupted NMDA-LTD show a relatively specific impairment in reversal learning in the MWM task (Nicholls et al., 2008; Kim et al., 2011; Dong et al., 2013). More detailed analysis of these rodent models will be needed to determine whether they also show impaired attention performance in the 5-CSRTT. 
A

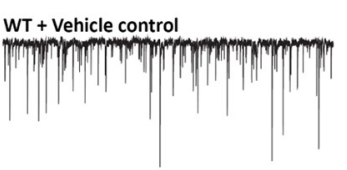

WT

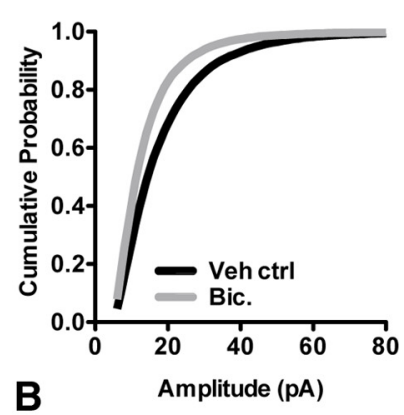

DMSO + Vehicle control

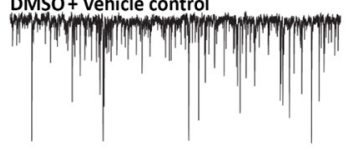

DMSO

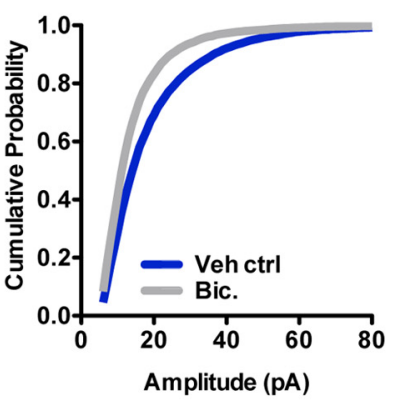

C

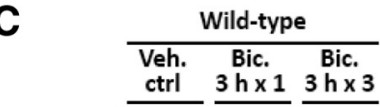

GluA1 - - - -

GluA2 -

Actin - - - -

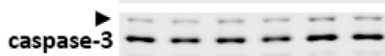

$\mathrm{Casp3}^{-1-}$

Veh. Bic. Bic.

ctrl $3 \mathrm{h \times 1} 3 \mathrm{h \times 3}$

GluA1 - - - - -

GluA2 - - - -

Actin - - - -

caspase-3
WT + Bicuculline (1)

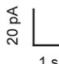

WT

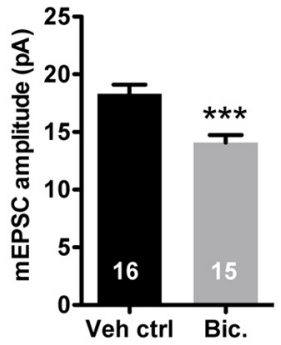

MSO + Bicuculline

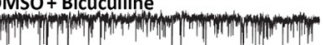

总

DMSO
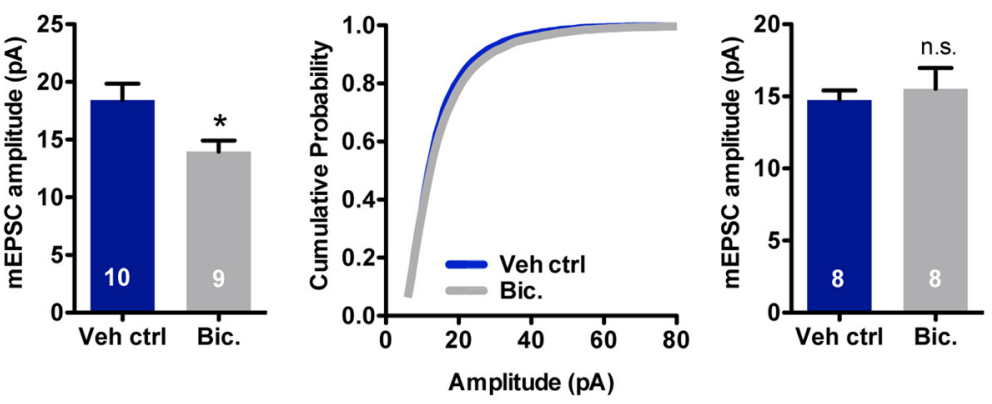

Casp3 $^{-1-}$

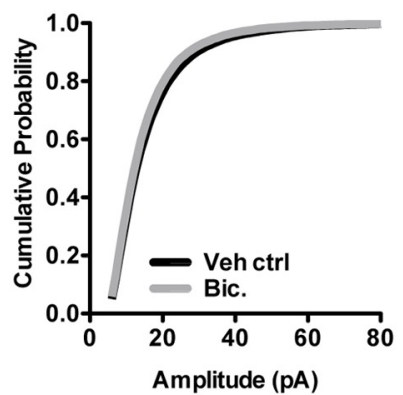

Z-DEVD-FMK+ Vehicle ctr

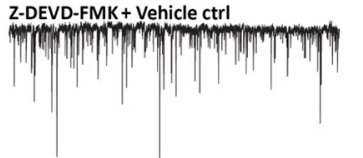

Z-DEVD-FMK
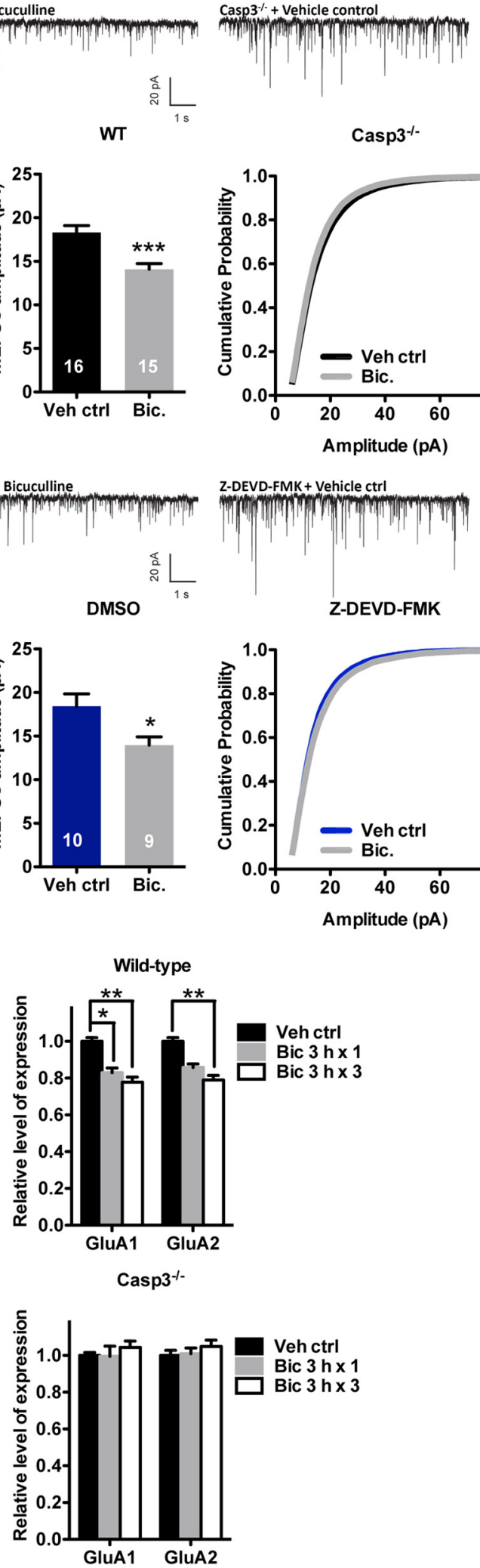

Figure 6. Effects of caspase-3 deficiency on synaptic homeostasis upon chronic repetitive stimuli. $\boldsymbol{A}, \boldsymbol{B}$, Homeostatic synaptic scaling during elevated network activity. Top panels, Representative whole-cell recording traces of mEPSCs. Bottom panels, Cumulative probability distribution plots or bar graphs of mEPSC amplitude. $C$, Immunoblotting (left panels) and quantification (right panels) of AMPA receptor subunits GluA1 and GluA2 expression, normalized to actin, in dissociated hippocampal neuron cultures. The arrows indicate an endogenous protein that cross-reacts with the antibodies. Bar graphs show the mean \pm SEM for 16 WT (DMSO), 15 WT [bicuculline (Bic)], 15 Casp3 ${ }^{-/-}$(DMSO), and 15 Casp3 ${ }^{-/-}$(Bic) cells (A); 10 WT (DMSO), 9 WT (Bic), 8 WT (Z-DEVD-FMK), and 8 WT (Bic/Z-DEVD-FMK) cells $(\boldsymbol{B})$; and 6 WT and 6 Casp3 ${ }^{-/-}$cultures $(\boldsymbol{C}) .{ }^{*} p<0.05,{ }^{* *} p<0.01,{ }^{* * *} p<0.001$ for treatment effect, by unpaired two-tailed $t$ test $(\boldsymbol{A}, \boldsymbol{B})$ or by Dunn's post-tests following Kruskal-Wallis test (C). Veh, Vehicle; ctrl, control. 
A

Naive
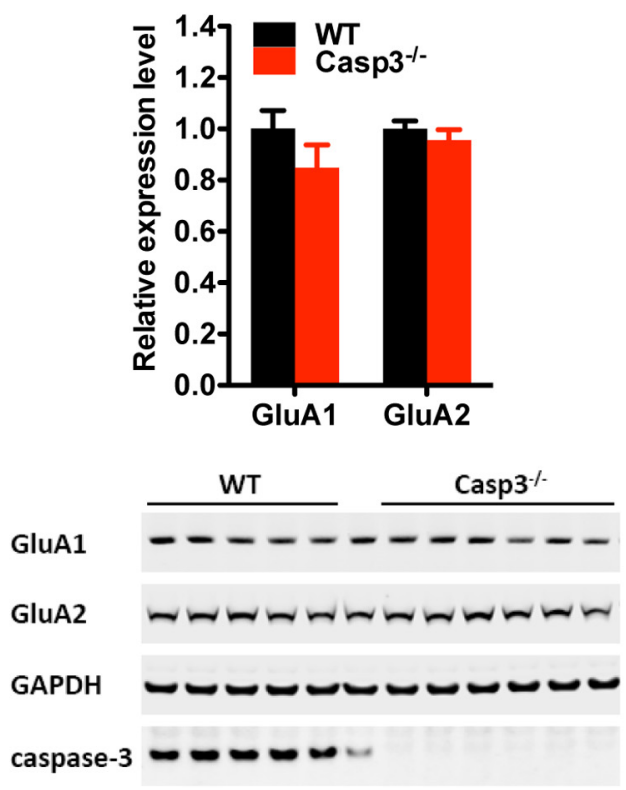

C
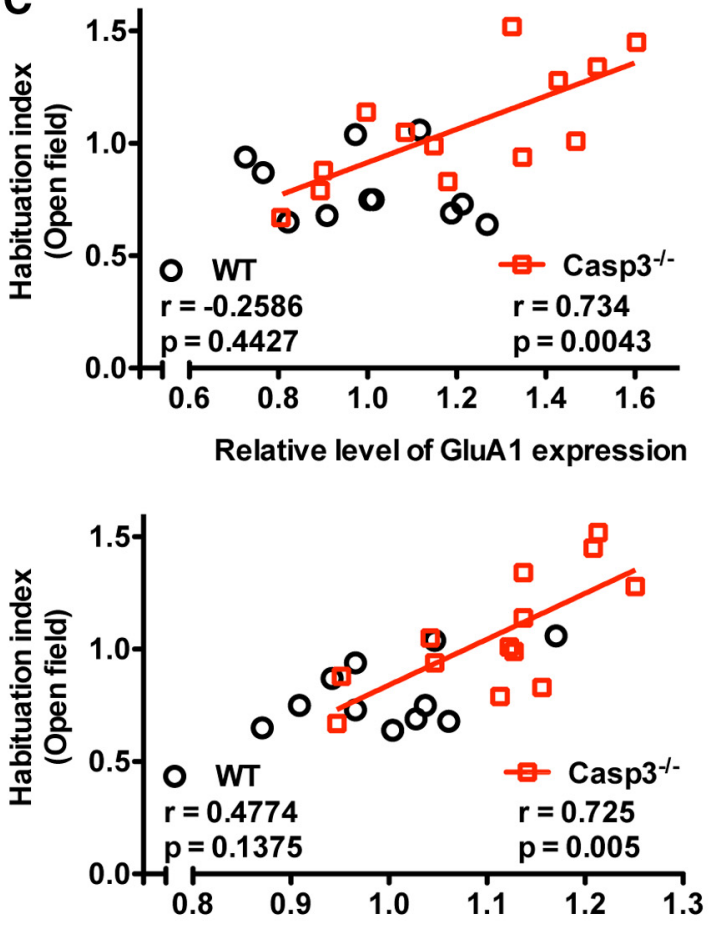

B

Experienced

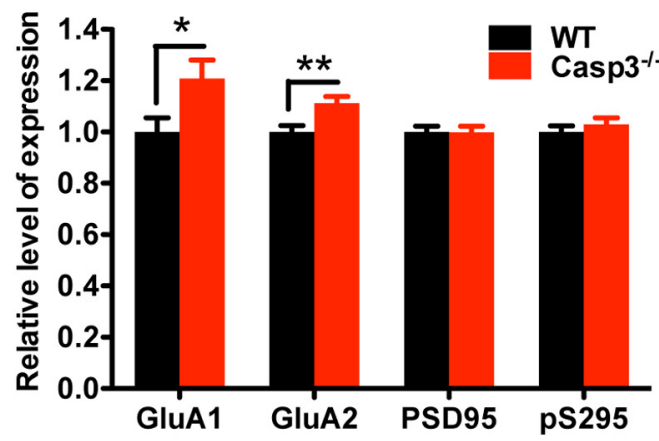

Experienced

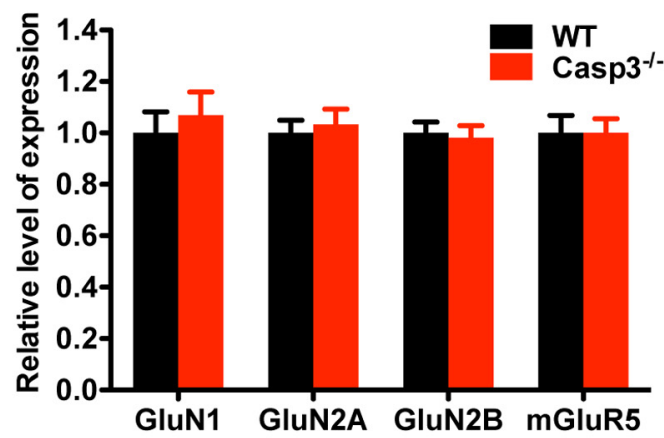

GluA1

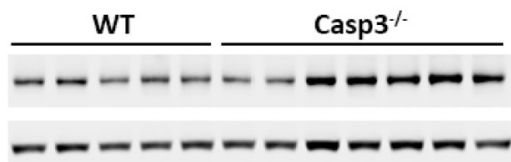

PSD95

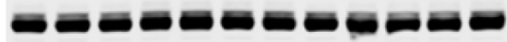

PSD95-pS295 -ーーーーーーーーーー

GluN1

GluN2A

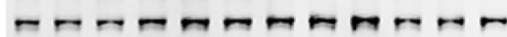

GluN2B

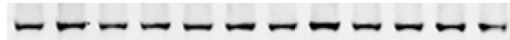

mGluR5

Actin

GAPDH

caspase-3
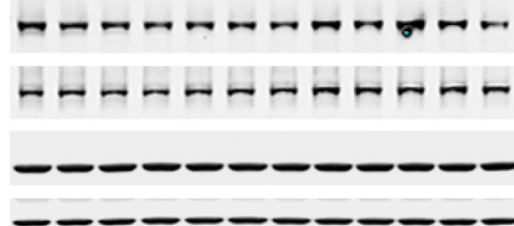

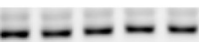

Figure 7. Effects of caspase-3 deficiency on homeostatic expression of hippocampal GluA1 and GluA2 upon repeated challenges with new behavioral testing. $A$, Immunoblotting (bottom) and quantification (top) of GluA1 and GluA2 expression, normalized to GAPDH, in the hippocampus of naive mice ( $\sim 11$ months of age). $B$, Immunoblotting (bottom panel) and quantification (top and middle panels) of GluA1, GluA2, PSD95, GluN1, GluN2A, GluN2B, and mGluR5 expression, normalized to GAPDH, in the hippocampus of experienced mice ( $\sim 11$ months of age). C, Relationship of relative protein levels of GluA1 (top) or GluA2 (bottom), with habituation index [(locomotion on day 4)/(locomotion on day 1)] in a novel open field. Bar graphs show the mean \pm SEM for 8 WT and 8 Casp3 ${ }^{-1-}$ mice $(\boldsymbol{A})$, and 11 WT and 13 Casp3 ${ }^{-1-}$ mice $(\boldsymbol{B}) .{ }^{*} p<0.05,{ }^{* *} p<0.01$ for genotype effect, by ANOVA.

Casp3 $3^{-1-}$ mice were slow to learn in a reversal condition involving visuospatial information in the MWM task (Fig. 3D), while quick to learn another reversal condition involving odor or tactile information in the ASST (Fig. 3G), indicating that deficits in reversal learning in Casp $3^{-1-}$ mice are likely to be specific to visuospatial information processing. However, to the best of our knowledge, our study is the first to describe these two reversal learning paradigms side by side. Hence, little is known about the relative sensitivity of these tests, and more studies will be needed to assess this possibility.

Apparent deficits during 5-CSRTT testing could be attributed either to impaired attention control or more general learning 
disabilities of this complex task. For Casp $3^{-1-}$ mice, it is unlikely that general learning abnormalities underlie their poor attention performance, as evidenced by their rapid acquisition of this task and normal performance on other cognitive tasks like MWM and fear conditioning. It has been reported that several genetically engineered mouse lines have poor performance across multiple learning paradigms while demonstrating normal attention performance in 5-CSRTT testing, suggesting doubly dissociable effects on these learning versus attention paradigms. For example, Fmrl knock-out mice acquire the 5-CSRTT at a much slower rate than their WT littermates during the training phase but, once trained, show comparable attention performance in the testing phase (Krueger et al., 2011). In addition, galanin transgenic mice show poor performance in the probe trials of the MWM task, while having normal acquisition and attention performance in the 5-CSRTT (Steiner et al., 2001; Wrenn et al., 2006).

Attention control is a complex system consisting of the following multiple cognitive processes: alertness, reorientation, and executive control (Petersen and Posner, 2012). Previous reports (Young et al., 2004; Guillem et al., 2011) show that, upon deletion of nicotinic acetylcholine receptor $\beta 2$ or $\alpha 7$ subunit, mice have increased omitted responses in the 5-CSRTT, but retain normal response accuracy and inhibition of impulsivity, which is consistent with a predominant effect of acetylcholine on cue alertness and detection. In contrast, Casp3 ${ }^{-1-}$ mice have enhanced impulsivity and reduced response accuracy (Fig. 2), while maintaining low omitted responses (data not shown). This suggests that caspase-3 deficiency disrupts reorienting and executive processes of attention control rather than alertness, and hence points to a suitable tool to study distinct elements of attention.

Habituation deficits are sometimes attributed to impaired recognition memory. However, since recognition memory and contextual memory appear intact in Casp3 $3^{-1-}$ mice (Fig. $4 F$; Table 1), a more likely explanation for their reduced habituation is a diminished capacity to downgrade the perceived salience of a recent novel experience. Defined as a decrease in response to repeated stimuli, habituation is a form of adaptive behavior, and a hallmark of selective attention (Tipper et al., 1989). When stimuli are repeated, reduction in neural activity in the brain can be observed, as measured by single-cell recording, fMRI, or EEG/ EMG, a phenomenon known as repetition suppression (GrillSpector et al., 2006). Neural mechanisms underlying repetition suppression are as yet unknown, but this work suggests that caspase-3-mediated synaptic weakening mechanisms, possibly including NMDA-LTD and/or homeostatic synaptic scaling, are involved in suppressing salience-induced neural activity, thereby facilitating habituation to repeated novel stimuli.

We provide evidence that caspase- 3 is required for the suppression of neural activity associated with novelty salience. In Casp $3^{-1-}$ mice, not only is novel environment-induced c-Fos expression abnormally augmented in dentate gyrus, but it also correlates with heightened behavioral response (Fig. 5 B, C). Likewise, when caspase- 3 is pharmacologically inhibited in songbirds, induction of the immediate early gene zenk in the auditory forebrain fails to attenuate upon repeated playing of a novel song (Huesmann and Clayton, 2006). Furthermore, weakening of synaptic strength has been shown to accompany repetitive novel stimuli, as demonstrated by reduced mEPSC frequency in Arc/ Arg3.1-expressing hippocampal neurons when wild-type mice are repeatedly exposed to a novel environment (Jakkamsetti et al., 2013). In Casp $3^{-1-}$ mice, however, AMPA receptor levels in hippocampus are higher than in WT mice following repeated chal- lenge with new behavior tasks, perhaps reflecting a failure to weaken synaptic strength (Fig. $7 B$ ).

Given the extensive overlap in molecular mechanisms between Hebbian plasticity and homeostatic synaptic plasticity (Vitureira and Goda, 2013), it is not surprising that both NMDALTD and homeostatic downscaling of synaptic strength have been implicated in habituation in rodents. Dong et al. (2012) recently showed that when novelty exploration-facilitated LTD is abolished in rats treated with an NMDA receptor antagonist or inhibitors of AMPA receptor endocytosis, subsequent habituation response is also blocked. In addition, 2-methyl-6(phenylethynyl)-pyridine (MPEP), an inverse agonist of mGluR5 that blocks bicuculline-induced homeostatic scaling and mGluRLTD (Hu et al., 2010), prevents behavioral habituation to a novel environment in rats (Popkirov and Manahan-Vaughan, 2011). Genetic studies have also demonstrated a correlation between habituation deficits and impaired homeostatic scaling, as reported for EphA4 receptor knock-out mice (Fu et al., 2011; Willi et al., 2012) and now in Casp3 $3^{-1-}$ mice (Fig. 6).

Our findings have implications that are relevant for understanding the neurobiology of attention control. Attention control is a complex system involving multiple anatomical networks. In keeping with neuroimaging data that demonstrated repetition suppression in hippocampus when attending to new rules or information (Graham et al., 2009; Zweynert et al., 2011), our data indicate a link, but not necessarily causality, between synaptic suppression in hippocampus and novelty-induced attention behavior. Nevertheless, caspase- 3 is ubiquitously expressed in the nervous system, raising the possibility that it may also mediate synaptic suppression in other brain regions and/or regulate attention processes in response to different demands. As our caspase- 3 knockout is not tissue restricted or inducible, this study does not differentiate between the acute versus the developmental effects of caspase-3 deficiency; nor does it define which region of the brain requires caspase-3 for proper functioning of attentional control. Several studies showed critical functions of caspase- 3 in the developing CNS. In flies, caspase- 3 mediates dendrite pruning during metamorphosis (Kuo et al., 2006; Williams et al., 2006); in Xenopus laevis tadpoles, it fine tunes the threshold of sensory experience-driven plasticity (i.e., metaplasticity; Chen et al., 2012). A more detailed analysis of conditional caspase-3 deficiency or rescue of caspase-3 expression in the Casp3 ${ }^{-1-}$ mice during the juvenile, adolescent, or adult stage may further elucidate the mechanisms underlying the development, maturation, and maintenance of cognitive adaptability.

\section{References}

Bari A, Robbins TW (2011) Animal models of ADHD. Curr Top Behav Neurosci 7:149-185. CrossRef Medline

Botvinick MM, Braver TS, Barch DM, Carter CS, Cohen JD (2001) Conflict monitoring and cognitive control. Psychol Rev 108:624-652. CrossRef Medline

Chen SX, Cherry A, Tari PK, Podgorski K, Kwong YK, Haas K (2012) The transcription factor MEF2 directs developmental visually driven functional and structural metaplasticity. Cell 151:41-55. CrossRef Medline

Collingridge GL, Peineau S, Howland JG, Wang YT (2010) Long-term depression in the CNS. Nat Rev Neurosci 11:459-473. CrossRef Medline

Corbetta M, Patel G, Shulman GL (2008) The reorienting system of the human brain: from environment to theory of mind. Neuron 58:306-324. CrossRef Medline

D’Amelio M, Sheng M, Cecconi F (2012) Caspase-3 in the central nervous system: beyond apoptosis. Trends Neurosci 35:700-709. CrossRef Medline

Davis GW (2006) Homeostatic control of neural activity: from phenomenology to molecular design. Annu Rev Neurosci 29:307-323. CrossRef Medline 
Desimone R (1996) Neural mechanisms for visual memory and their role in attention. Proc Natl Acad Sci U S A 93:13494-13499. CrossRef Medline

Desimone R, Duncan J (1995) Neural mechanisms of selective visual attention. Annu Rev Neurosci 18:193-222. CrossRef Medline

Dickman DK, Davis GW (2009) The schizophrenia susceptibility gene dysbindin controls synaptic homeostasis. Science 326:1127-1130. CrossRef Medline

Dong Z, Gong B, Li H, Bai Y, Wu X, Huang Y, He W, Li T, Wang YT (2012) Mechanisms of hippocampal long-term depression are required for memory enhancement by novelty exploration. J Neurosci 32:1198011990. CrossRef Medline

Dong Z, Bai Y, Wu X, Li H, Gong B, Howland JG, Huang Y, He W, Li T, Wang YT (2013) Hippocampal long-term depression mediates spatial reversal learning in the Morris water maze. Neuropharmacology 64:65-73. CrossRef Medline

Ertürk A, Wang Y, Sheng M (2014) Local pruning of dendrites and spines by caspase-3-dependent and proteasome-limited mechanisms. J Neurosci 34:1672-1688. CrossRef Medline

Ewen JB, Shapiro BK (2005) Disorders of attention or learning in neurodevelopmental disorders. Semin Pediatr Neurol 12:229-241. CrossRef Medline

Fernando AB, Robbins TW (2011) Animal models of neuropsychiatric disorders. Annu Rev Clin Psychol 7:39-61. CrossRef Medline

Fu AK, Hung KW, Fu WY, Shen C, Chen Y, Xia J, Lai KO, Ip NY (2011) APC(Cdh1) mediates EphA4-dependent downregulation of AMPA receptors in homeostatic plasticity. Nat Neurosci 14:181-189. CrossRef Medline

Ghanizadeh A (2011) Sensory processing problems in children with ADHD, a systematic review. Psychiatry Investig 8:89-94. CrossRef Medline

Graham S, Phua E, Soon CS, Oh T, Au C, Shuter B, Wang SC, Yeh IB (2009) Role of medial cortical, hippocampal and striatal interactions during cognitive set-shifting. Neuroimage 45:1359-1367. CrossRef Medline

Grill-Spector K, Henson R, Martin A (2006) Repetition and the brain: neural models of stimulus-specific effects. Trends Cogn Sci 10:14-23. CrossRef Medline

Guillem K, Bloem B, Poorthuis RB, Loos M, Smit AB, Maskos U, Spijker S, Mansvelder HD (2011) Nicotinic acetylcholine receptor beta2 subunits in the medial prefrontal cortex control attention. Science 333:888-891. CrossRef Medline

Hu JH, Park JM, Park S, Xiao B, Dehoff MH, Kim S, Hayashi T, Schwarz MK, Huganir RL, Seeburg PH, Linden DJ, Worley PF (2010) Homeostatic scaling requires group I mGluR activation mediated by Homer 1 a. Neuron 68:1128-1142. CrossRef Medline

Huesmann GR, Clayton DF (2006) Dynamic role of postsynaptic caspase-3 and BIRC4 in zebra finch song-response habituation. Neuron 52:10611072. CrossRef Medline

Hyman BT, Yuan J (2012) Apoptotic and nonapoptotic roles of caspases in neuronal physiology and pathophysiology. Nat Rev Neurosci 13:395406. CrossRef Medline

Jakkamsetti V, Tsai NP, Gross C, Molinaro G, Collins KA, Nicoletti F, Wang KH, Osten P, Bassell GJ, Gibson JR, Huber KM (2013) Experienceinduced Arc/Arg3.1 primes CA1 pyramidal neurons for metabotropic glutamate receptor-dependent long-term synaptic depression. Neuron 80:72-79. CrossRef Medline

Jansiewicz EM, Newschaffer CJ, Denckla MB, Mostofsky SH (2004) Impaired habituation in children with attention deficit hyperactivity disorder. Cogn Behav Neurol 17:1-8. CrossRef Medline

Jurado MB, Rosselli M (2007) The elusive nature of executive functions: a review of our current understanding. Neuropsychol Rev 17:213-233. CrossRef Medline

Kemp A, Manahan-Vaughan D (2008) The hippocampal CA1 region and dentate gyrus differentiate between environmental and spatial feature encoding through long-term depression. Cereb Cortex 18:968-977. CrossRef Medline

Kim JI, Lee HR, Sim SE, Baek J, Yu NK, Choi JH, Ko HG, Lee YS, Park SW, Kwak C, Ahn SJ, Choi SY, Kim H, Kim KH, Backx PH, Bradley CA, Kim E, Jang DJ, Lee K, Kim SJ, et al. (2011) PI3Kgamma is required for NMDA receptor-dependent long-term depression and behavioral flexibility. Nat Neurosci 14:1447-1454. CrossRef Medline

Krueger DD, Osterweil EK, Chen SP, Tye LD, Bear MF (2011) Cognitive dysfunction and prefrontal synaptic abnormalities in a mouse model of fragile X syndrome. Proc Natl Acad Sci U S A 108:2587-2592. CrossRef Medline

Kuo CT, Zhu S, Younger S, Jan LY, Jan YN (2006) Identification of E2/E3 ubiquitinating enzymes and caspase activity regulating Drosophila sensory neuron dendrite pruning. Neuron 51:283-290. CrossRef Medline

Le Pichon CE, Dominguez SL, Solanoy H, Ngu H, Lewin-Koh N, Chen M, Eastham-Anderson J, Watts R, Scearce-Levie K (2013) EGFR inhibitor erlotinib delays disease progression but does not extend survival in the SOD1 mouse model of ALS. PLoS One 8:e62342. CrossRef Medline

Li Z, Jo J, Jia JM, Lo SC, Whitcomb DJ, Jiao S, Cho K, Sheng M (2010) Caspase-3 activation via mitochondria is required for long-term depression and AMPA receptor internalization. Cell 141:859-871. CrossRef Medline

Lustig C, Kozak R, Sarter M, Young JW, Robbins TW (2013) CNTRICS final animal model task selection: control of attention. Neurosci Biobehav Rev 37:2099-2110. CrossRef Medline

Marzocchi GM, Oosterlaan J, Zuddas A, Cavolina P, Geurts H, Redigolo D, Vio C, Sergeant JA (2008) Contrasting deficits on executive functions between ADHD and reading disabled children. J Child Psychol Psychiatry 49:543-552. CrossRef Medline

Nicholls RE, Alarcon JM, Malleret G, Carroll RC, Grody M, Vronskaya S, Kandel ER (2008) Transgenic mice lacking NMDAR-dependent LTD exhibit deficits in behavioral flexibility. Neuron 58:104-117. CrossRef Medline

Paxinos G, Franklin KBJ (2012) The mouse brain in stereotaxic coordinates, 4 Ed. New York: Elsevier.

Petersen SE, Posner MI (2012) The attention system of the human brain: 20 years after. Annu Rev Neurosci 35:73-89. CrossRef Medline

Popkirov SG, Manahan-Vaughan D (2011) Involvement of the metabotropic glutamate receptor mGluR5 in NMDA receptor-dependent, learning-facilitated long-term depression in CA1 synapses. Cereb Cortex 21:501-509. CrossRef Medline

Qiu Z, Sylwestrak EL, Lieberman DN, Zhang Y, Liu XY, Ghosh A (2012) The Rett syndrome protein MeCP2 regulates synaptic scaling. J Neurosci 32: 989-994. CrossRef Medline

Robbins TW (2002) The 5-choice serial reaction time task: behavioural pharmacology and functional neurochemistry. Psychopharmacology 163:362-380. CrossRef Medline

Saab BJ, Georgiou J, Nath A, Lee FJ, Wang M, Michalon A, Liu F, Mansuy IM, Roder JC (2009) NCS-1 in the dentate gyrus promotes exploration, synaptic plasticity, and rapid acquisition of spatial memory. Neuron 63:643656. CrossRef Medline

Shiels K, Hawk LW Jr (2010) Self-regulation in ADHD: the role of error processing. Clin Psychol Rev 30:951-961. CrossRef Medline

Siddoway B, Hou H, Xia H (2014) Molecular mechanisms of homeostatic synaptic downscaling. Neuropharmacology 78:38-44. CrossRef Medline

Soden ME, Chen L (2010) Fragile X protein FMRP is required for homeostatic plasticity and regulation of synaptic strength by retinoic acid. J Neurosci 30:16910-16921. CrossRef Medline

Steiner RA, Hohmann JG, Holmes A, Wrenn CC, Cadd G, Juréus A, Clifton DK, Luo M, Gutshall M, Ma SY, Mufson EJ, Crawley JN (2001) Galanin transgenic mice display cognitive and neurochemical deficits characteristic of Alzheimer's disease. Proc Natl Acad Sci U S A 98:4184-4189. CrossRef Medline

Tipper SP, Bourque TA, Anderson SH, Brehaut JC (1989) Mechanisms of attention: a developmental study. J Exp Child Psychol 48:353-378. CrossRef Medline

Toro R, Konyukh M, Delorme R, Leblond C, Chaste P, Fauchereau F, Coleman M, Leboyer M, Gillberg C, Bourgeron T (2010) Key role for gene dosage and synaptic homeostasis in autism spectrum disorders. Trends Genet 26:363-372. CrossRef Medline

Turrigiano G (2012) Homeostatic synaptic plasticity: local and global mechanisms for stabilizing neuronal function. Cold Spring Harb Perspect Biol 4:a005736. CrossRef Medline

Turrigiano GG, Leslie KR, Desai NS, Rutherford LC, Nelson SB (1998) Activity-dependent scaling of quantal amplitude in neocortical neurons. Nature 391:892-896. CrossRef Medline

Vitureira N, Goda Y (2013) Cell biology in neuroscience: the interplay between Hebbian and homeostatic synaptic plasticity. J Cell Biol 203:175186. CrossRef Medline

Võikar V, Vasar E, Rauvala H (2004) Behavioral alterations induced by re- 
peated testing in C57BL/6J and 129S2/Sv mice: implications for phenotyping screens. Genes Brain Behav 3:27-38. CrossRef Medline

Weissman DH, Roberts KC, Visscher KM, Woldorff MG (2006) The neural bases of momentary lapses in attention. Nat Neurosci 9:971-978. CrossRef Medline

Williams DW, Kondo S, Krzyzanowska A, Hiromi Y, Truman JW (2006) Local caspase activity directs engulfment of dendrites during pruning. Nat Neurosci 9:1234-1236. CrossRef Medline

Willi R, Winter C, Wieske F, Kempf A, Yee BK, Schwab ME, Singer P (2012) Loss of EphA4 impairs short-term spatial recognition memory performance and locomotor habituation. Genes Brain Behav. Advance online publication. Retrieved December 24, 2014. doi:10.1111/j.1601183X.2012.00842.x. CrossRef Medline
Wrenn CC, Turchi JN, Schlosser S, Dreiling JL, Stephenson DA, Crawley JN (2006) Performance of galanin transgenic mice in the 5-choice serial reaction time attentional task. Pharmacol Biochem Behav 83:428-440. CrossRef Medline

Young JW, Finlayson K, Spratt C, Marston HM, Crawford N, Kelly JS, Sharkey J (2004) Nicotine improves sustained attention in mice: evidence for involvement of the alpha7 nicotinic acetylcholine receptor. Neuropsychopharmacology 29:891-900. CrossRef Medline

Zweynert S, Pade JP, Wüstenberg T, Sterzer P, Walter H, Seidenbecher CI, Richardson-Klavehn A, Düzel E, Schott BH (2011) Motivational salience modulates hippocampal repetition suppression and functional connectivity in humans. Front Hum Neurosci 5:144. CrossRef Medline 